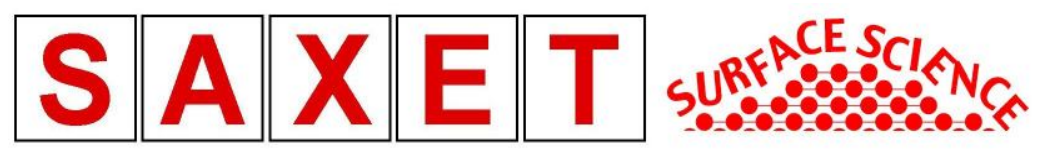

Final Report

\title{
Activation Layer Stabilization of High Polarization Photocathodes in Sub-Optimal RF Gun Environments
}

\author{
Saxet Surface Science \\ Contract DE-FG02-07ER84832 \\ Gregory A. Mulhollan, Principal Investigator \\ Key Personnel: John Bierman \\ Subcontractor: Robert Kirby* \\ Subcontracting agency: SLAC National Accelerator Laboratory \\ Subcontracting personnel: Takashi Maruyama ${ }^{\S}$, Steven Sun* and Piero Pianetta*
}




\section{Executive Summary}

A rapid-change gas manifold system was installed onto the Saxet photocathode test system. Specific activation recipes for bulk, $100 \mathrm{~nm}$ thick MBE grown and high polarization III-V photocathode material have been developed which mitigate the effects of exposure to background gasses. Lifetime data using four representative gasses were acquired for bulk GaAs, $100 \mathrm{~nm}$ unstrained GaAs and strained superlattice GaAs/GaAsP, all activated both with Cs and then $\mathrm{Cs}$ and Li (bi-alkali). Each photoemitter showed marked resilience improvement when activated using the bi-alkali recipe compared to the standard single alkali recipe. A dual alkali activation system at SLAC was constructed, baked and commissioned with the purpose of performing spin-polarization measurements on electrons emitted from the bi-alkali activated surfaces. An end station at SSRL was configured with the required sources for energy resolved photoemission measurements on the bi-alkali activated and $\mathrm{CO}_{2}$ dosed surfaces.

The bi-alkali recipes were successfully implemented at SLAC/SSRL. Measurements at SLAC of the photoelectron spin-polarization from the modified activation surface showed no sign of a change in value compared to the standard activated material, i.e., no ill effects. Analysis of photoemission data indicates that the addition of $\mathrm{Li}$ to the activation layer results in a multi-layer structure. The presence of $\mathrm{Li}$ in the activation layer also acts as an inhibitor to $\mathrm{CO}_{2}$ absorption, hence better lifetimes in worse vacuum were achieved. The bi-alkali activation has been tested on $\mathrm{O}_{2}$ activated $\mathrm{GaAs}$ for comparison with $\mathrm{NF}_{3}$ activated surfaces. Comparable resilience to $\mathrm{CO}_{2}$ exposure was achieved for the $\mathrm{O}_{2}$ activated surface.

An RF PECVD amorphous silicon growth system was modified to allow high temperature heat cleaning of GaAs substrates prior to film deposition. Growth versus thickness data were collected. Very thin amorphous silicon germanium layers were optimized to exhibit good behavior as an electron emitter. Growth of the amorphous silicon germanium films on the above substrates was fine tuned with respect to time and power to moderate plasma damage to the photo-generating layer. Auger electron spectroscopy was used to analyze the composition and thickness of the emitter layers. AFM studies showed conformal growth on the GaAs substrates. Measurements at SLAC on the photoemitted electrons from high polarization substrates coated with amorphous silicon germanium indicated an $\sim 10 \%$ relative drop in spin-polarization at the wavelength corresponding to the maximum spin-polarization when compared to the uncoated material, 


\section{Task Results Summary}

1. Modification of Saxet cathode test chamber

A gas panel was designed and constructed so that one gas at a time could be introduced through the existing gas dosing leak valve. Four gasses and regulators, $\mathrm{CO}_{2}$ (for comparison with the Phase I results), $\mathrm{CO}$ (for comparison with $\mathrm{CO}_{2}$ ), $\mathrm{O}_{2}$ (as a strong oxidizer) and $\mathrm{CH}_{4}$ (as an ever present background gas in ion pumped UHV systems) were ordered and installed on the panel.

\section{Acquire test wafers}

Both the unstrained high polarization wafers were ordered and received.

\section{Commission SLAC's dual alkali activation and shuttle system}

SLAC's two alkali equipped activation chamber was assembled, baked out and commissioned. Connection of the activation/shuttle unit to the electron polarimeter chamber allows the bi-alkali activated sample to be transferred under vacuum for spin-polarization measurements.

\section{Measure reactivity of best recipe activated photocathodes}

Specific bi-alkali activation recipes for bulk, $100 \mathrm{~nm}$ thick MBE grown and high polarization III$\mathrm{V}$ photocathode material were developed. Each material had reactivity for the four gasses of (1) measured for the single- and bi-alkali activated surfaces. In all cases the bi-alkali surface exhibited superior performance.

5. Measure electron spin-polarization of bi-alkali activated photoemitters

Using the dedicated dual alkali source chamber at SLAC, the electron spin polarization was measured to be the same from the bi-alkali activated surfaces as for the standard, single-alkali activated ones.

\section{Photoemission characterization of $\mathrm{Cs}+\mathrm{Li}$ activated surfaces}

Extensive photoemission studies of the $\mathrm{Cs}$ and the $\mathrm{Cs}+\mathrm{Li}$ activated surfaces were carried out. The layer dependent structure of the activation layer was derived by angular dependent measurements. It was shown that the presence of the $\mathrm{Li}$ in the activation layer inhibits the uptake of $\mathrm{CO}_{2}$.

\section{Growth and testing of a-Si on GaAs as robust emitter layer}

The growth of a-SiGe was optimized for use as an electron emission layer. This included minimizing damage to the underlying photogenerating layer and careful optimization of the layer thickness and composition. The $\mathrm{Cs}+\mathrm{Li}$ activated surfaces with a-SiGe films had marked improvement in $\mathrm{CO}_{2}$ resilience over the Cs only activated surfaces. Measurements at SLAC on the coated high-polarization photocathode did exhibit a decrease in electron spin-polarization at the maximum value, possibly due to near surface trapping. 


\section{S $|\mathbf{A}| \mathbf{X}|\mathbf{E}| \mathbf{T} \mid$}

Products and technology transfer activities

Commercialization started by:

Contact with a major night vision tube manufacturer has been successfully made. A site visit is planned in early 2011 to begin technology transfer of the new activation procedure to their test laboratory.

$\underline{\text { Results were presented at: }}$

Workshop on Sources of Polarized Electrons and High Brightness Electron Beams, October 1-3, 2008, CEBAF Center, Jefferson Lab, Newport News, VA.

with a conference paper appearing in:

G. A. Mulhollan and J. C. Bierman, Recent Progress toward Robust Photocathodes, 18th International Spin Physics Symposium, Charlottesville, Virginia, 6-11 October 2008, AIP Conference Proceedings, Vol. 1149, Crabb, D.G.; Prok, Y.; Poelker, M.; Liuti, S.; Day, D.B.; Zheng, X. (Eds.) 2009, 1027.

The Phase I results were published in:

G. A. Mulhollan, J. C. Bierman, "Enhanced chemical immunity for negative electron affinity GaAs photoemitters", J. Vac. Sci. Technol. A 26, 1195 (2008).

The photoemission results were published in:

Y. Sun, R. E. Kirby, T. Maruyama, G. A. Mulhollan, J. C. Bierman and P. Pianetta, The Surface Activation Layer of GaAs Negative Electron Affinity Photocathode Activated by Cs, Li, and $\mathrm{NF}_{3}$, Appl. Phys. Lett. 95, 174109 (2009).

A US Patent Application:

US20090322222 has been submitted to and published by the US Patent Office.

Saxet participated in a DOE sponsored marketing effort:

with Foresight Science \& Technology, Inc. Contact with a major night vision tube manufacturer resulted.

A comprehensive paper detailing much of the work in this report is in progress. 


\section{Task Work and Results Detailed, Chronological}

\section{Modify Saxet chamber and acquire dosing gasses}

In order to not interrupt the use of the main GaAs photocathode yield test system, an external gas panel was designed and constructed so that one gas at a time could be introduced through the existing gas dosing leak valve. That valve is separate from the activation gas leak valve. The panel was constructed with all metal sealing surfaces and bakeable valves. Four gasses and regulators, $\mathrm{CO}_{2}$ (for comparison with the Phase I results), $\mathrm{CO}$ (for comparison with $\mathrm{CO}_{2}$ ), $\mathrm{O}_{2}$ (as a strong oxidizer) and $\mathrm{CH}_{4}$ (as an ever present background gas in ion pumped UHV systems) were ordered and installed on the panel. Figure 1 below shows the panel after leak checking, but before baking.



Figure 1. Rapid-change gas panel after all lines were installed and leak tested. The KF port (shown blanked, in center) was used for exhausting the manifold between gas changes.

Figure 2 shows the panel under vacuum up to the gas bottle valves. The manifold and lines connecting to the regulators were baked for two days at $\mathrm{T} \geq 125^{\circ} \mathrm{C}$ to remove water vapor from the system. Following this bake, the panel was installed inside the support frame of the cathode test system. This location provided a "bump-proof" environment for the bottles and regulators. A final bake including the manifold and line which leads to the dosing valve concluded the installation. With this setup, the selected gas for dosing is first introduced into the central manifold, which is isolated from atmosphere by a right angle all-metal sealing valve, then into the line that runs to the dosing leak valve. 


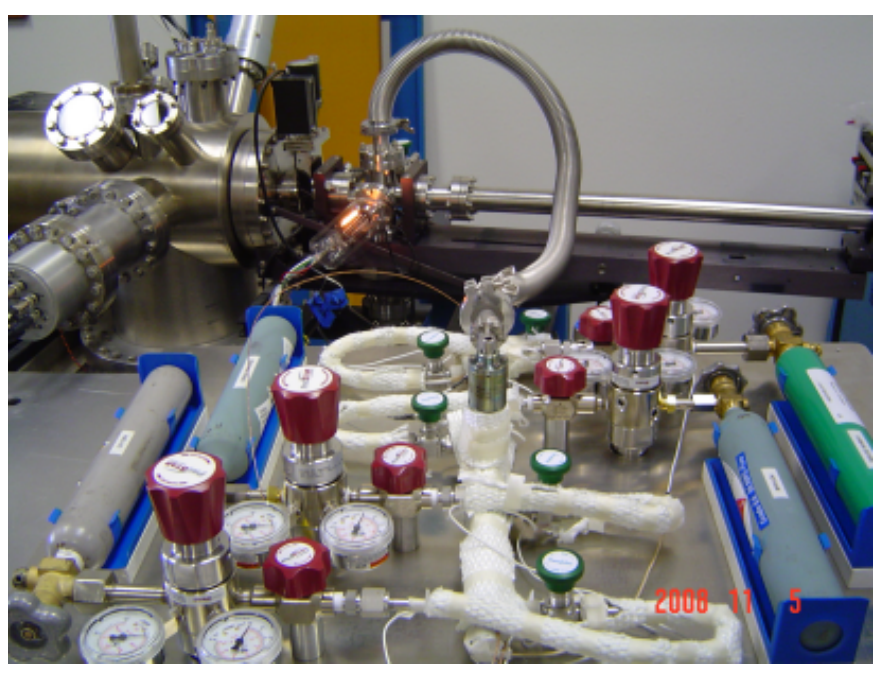

Figure 2. Gas panel under bake. Pumping was through a bellows attached to a dry turbo/scroll pump combination on the loadlock of Saxet's CMA system.

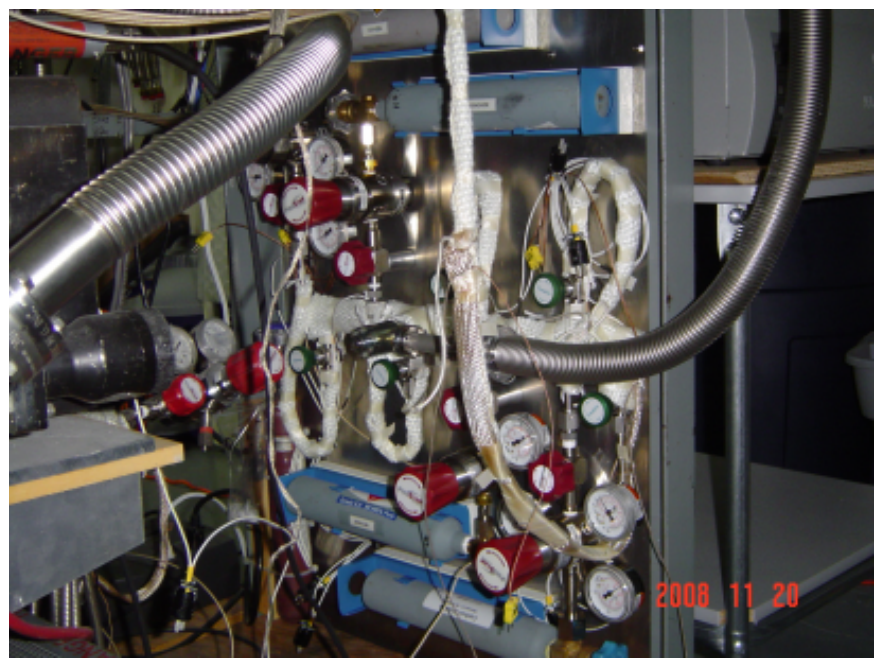

Figure 3. Gas panel installed and connected in the GaAs test chamber frame.

To effect a gas change, a dry pump station, which achieves low $10^{-7}$ Torr vacuum, is allowed to pump the connection bellows (right side of figure 3) down to the closed right angle valve overnight. The following day, the line up to the gas dosing leak valve is evacuated via the manifold for one hour. After these lines are evacuated, the selected gas is swapped in by charging the manifold and then the line leading to the dosing valve. After filling that line, the manifold and bellows leading to the regulator containing the new gas is evacuated, leaving only the regulators and the line leading to the dosing valve filled. No sign of any gas cross contamination 
or water vapor has been observed on the system RGA during gas dosing. Vacuum level is monitored with a cold cathode gauge attached to the dry pump station.

\section{Order and receive test wafers}

Both the unstrained, $100 \mathrm{~nm}$ thick MBE grown GaAs and the high polarization wafers were ordered and received. Each type of material was used for tests at Saxet (see below) for determining the most usable dual alkali activation recipes. The $100 \mathrm{~nm}$, low polarization material was also used at SLAC for polarization measurements on the single and dual alkali activated material. This material, along with existing bulk stock was employed in the SSRL photoemission measurements. The SVT high polarization material was used for characterization of the activation recipe (see below) for such material. A similar material was used at SLAC for some of the polarization tests; the material used at Saxet was made available for tests at SLAC for polarization effects caused by activation- or photoemitting-layer changes.

Assemble, bake and commission SLAC chamber

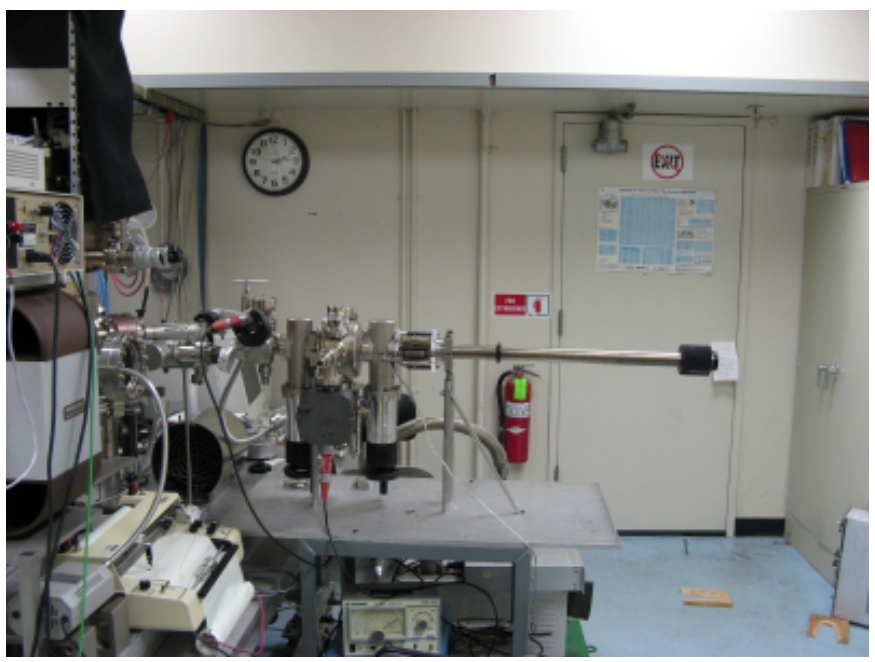

Figure 4. Side view of the SLAC sample activation and shuttle system which is being used for the dual alkali GaAs activations. This system attaches to the electron polarization measurement chamber on the left. Visible, from right to left, are the magnetic transporter, isolation valve, activation chamber (incorporating heat cleaning and $\mathrm{Cs}$ and $\mathrm{Li}$ alkali sources), isolation valve and wafer introduction port.

SLAC's two alkali equipped activation chamber is assembled, baked out, and commissioned (Figures 4 and 5). An initial, sacrificial, bulk GaAs wafer was heat cleaned in situ (Figure 6) and activated with Cs alone for historical comparison. The chart record of the activation is shown in 
Figure 7. The peak quantum efficiency of $1.2 \%$ with $650 \mathrm{~nm}$ illumination is consistent with historical Cs-only activations. Next, the wafer was re-heat cleaned and dual activated; finally, the sacrificial wafer was replaced with a new wafer, heat cleaned and dual activated. Following connection of the activation/shuttle unit to the electron polarimeter chamber, samples were transferred under vacuum to the main test chamber for spin-polarization measurements.

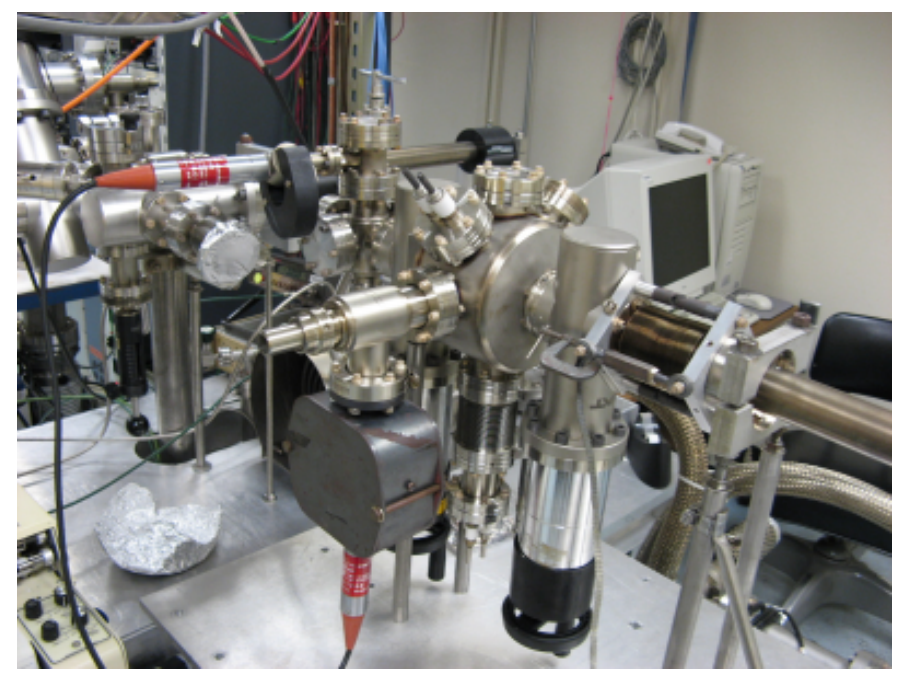

Figure 5. Another view of the SLAC dual alkali activation system.

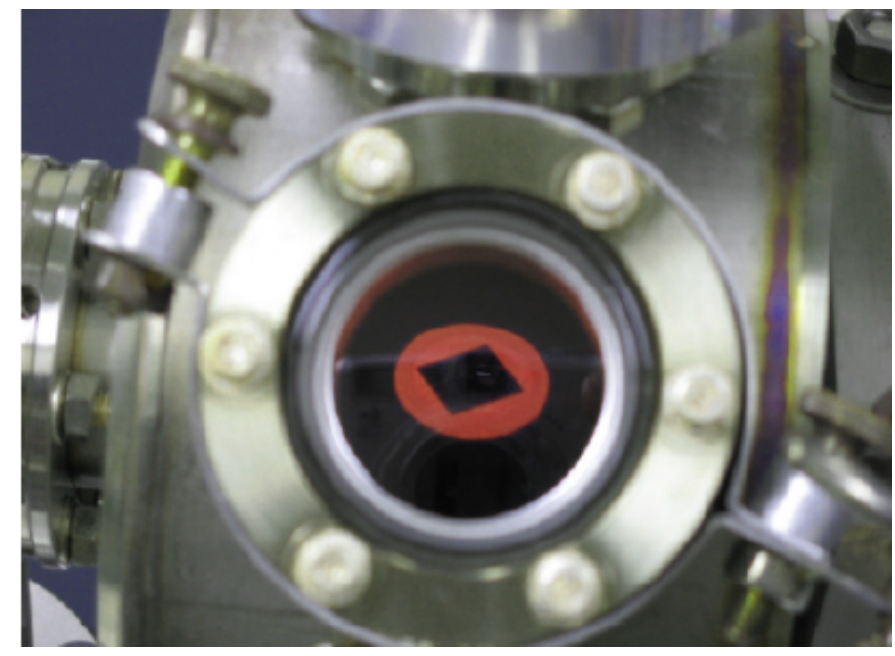

Figure 6. Image of a wafer during heat cleaning. The sample is the black square. 
DE-FG02-07ER84832

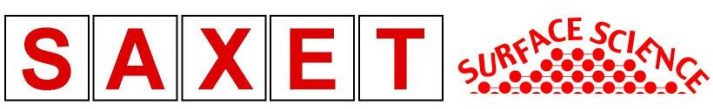

Activation Layer Stabilization of High Polarization Photocathodes in Sub-Optimal RF Gun Environments

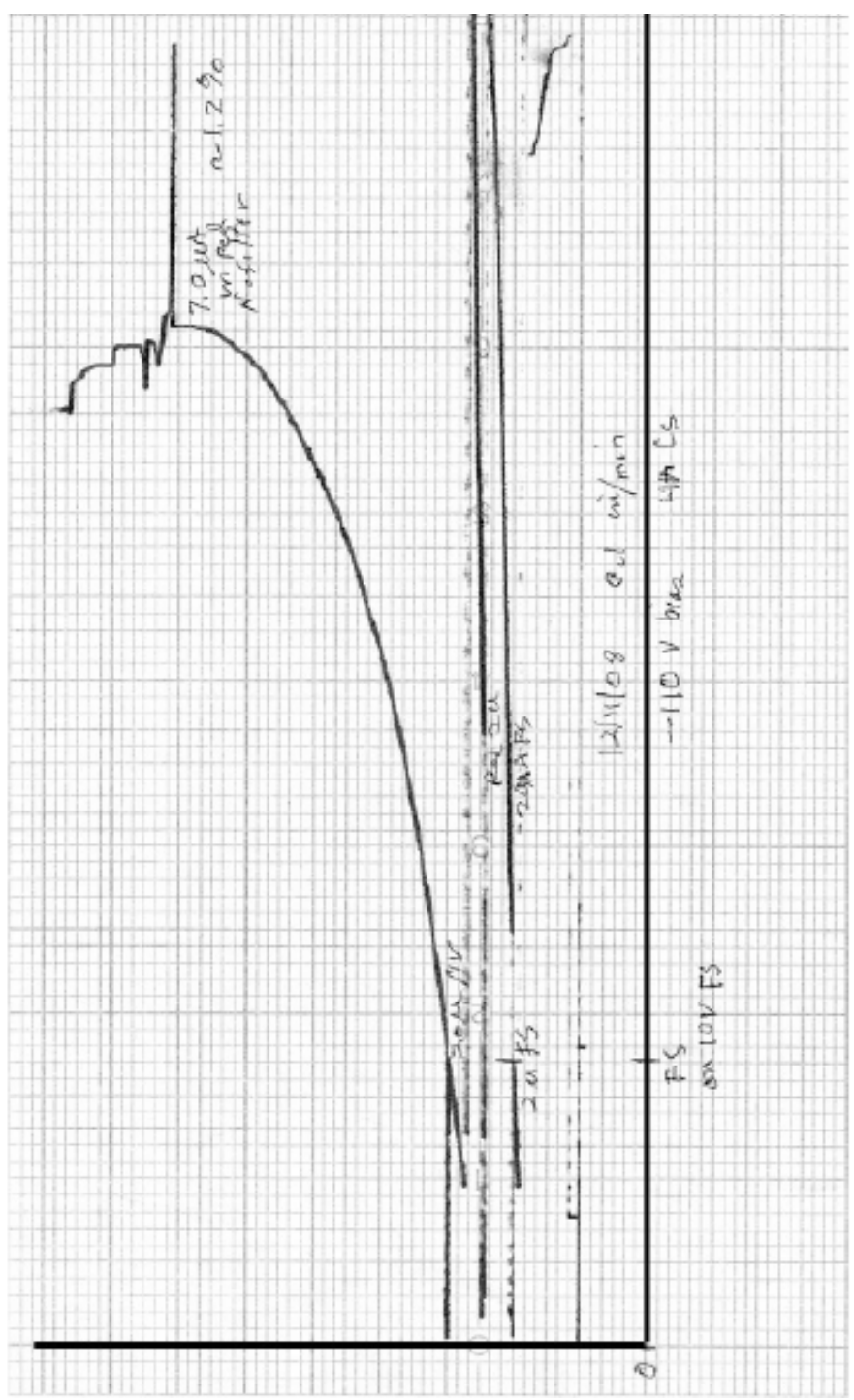

Figure 7. Chart recorder of Cs-only activation, representing about $30 \mathrm{~min}$ of elapsed time, showing that the quantum efficiency reaches $1.2 \%$ with $650 \mathrm{~nm}$ illumination. Time is on the horizontal axis, later times are to the left.

Following commissioning of the dual alkali activation system, operational details for the new activation system and the transport methodology were determined. One initial issue was large ion current from the Li channels. The high ion current was due to the relatively higher operating current for these getter sources compared to that for Cs, i.e., 6.4 A versus 3.6 A. The proximity of the getter sources in the dual alkali activation chamber also increased the capture efficiency of the positive ions to the photocathode. The size of the ion current was sufficient to mask the starting photocurrent, thereby making it problematic to determine the starting point and thus the actual total deposition time for the $\mathrm{Cs}$ and $\mathrm{Li}$ in the first stage of codeposition. This was 
overcome by changing the current measurement method from a direct current type to a light modulated one. An optical chopper was acquired and attached to the illumination port (figure 8) with its reference and the photocurrent signal fed to a lockin amplifier. In this way, the ion current signal was suppressed.

With the ion signal eliminated, test activations on bulk and $100 \mathrm{~nm}$ MBE GaAs were performed using the Saxet recipe for the bi-alkali activations. Good quality activations in the SMS chamber were achieved, but transport into the polarization test chamber resulted in greatly diminished yields. The culprit was traced via RGA to water vapor originating in the polarization chamber loadlock; it gets opened and exposed to air for sample insertion. Greatly improved transport (low yield loss) from the SMS chamber to the polarization test chamber was achieved by baking the loadlock arm once a new photocathode was installed into the SMS system.

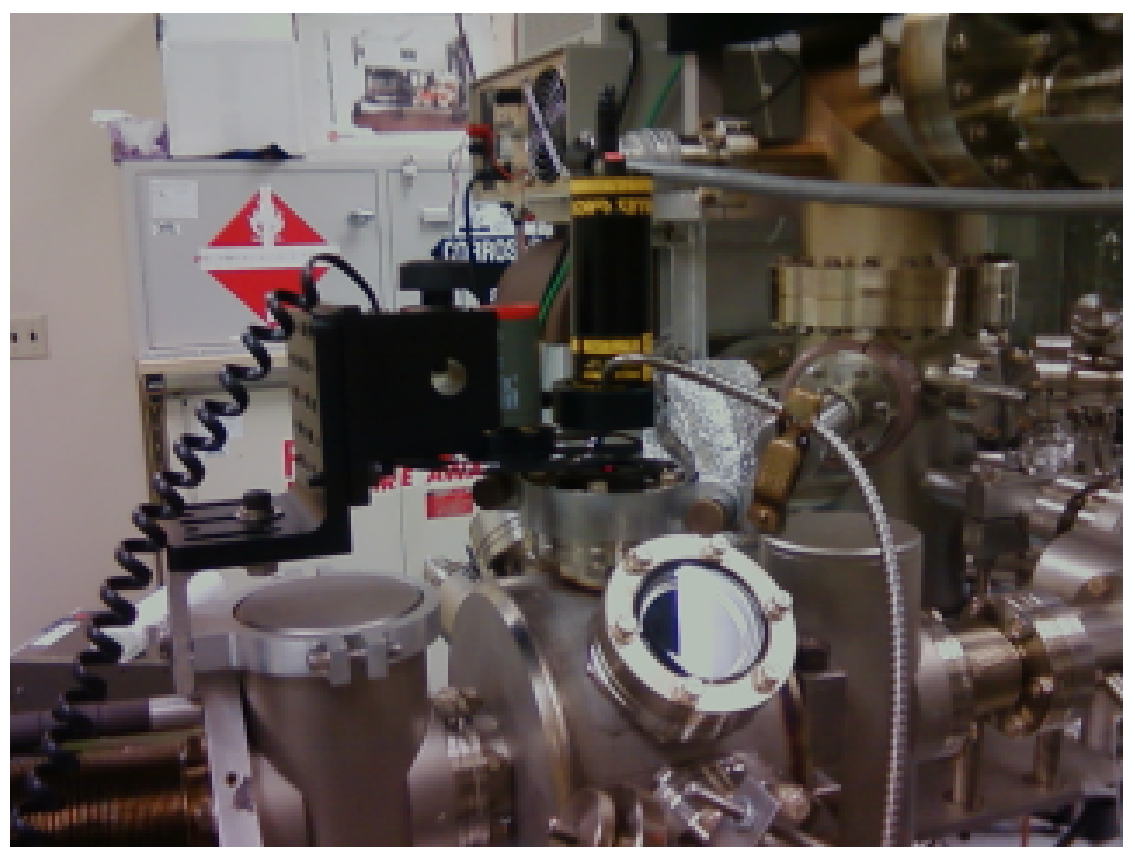

Figure 8. Side view of the SLAC sample activation chamber which was used for the dual alkali GaAs activations. This system was attached to the electron polarization measurement chamber loadlock. Visible, in center, is the diode laser and optical chopper used for activation.

\section{Measure reactivity of best recipe activated photocathodes}

A summary plot showing the yield decay for the four different gasses using $\mathrm{Cs}$ and $\mathrm{Cs}+\mathrm{Li}$ activations on bulk GaAs is shown below in fig. 9. Per standard methods, the activations were started with a white light source, then finished with a HeNe laser. Photocurrent was kept low at all times by use of neutral density filters to minimize electron beam induced desorption. 
Following activation, the photocathodes were allowed to "rest" overnight so that the chamber base pressure could recover to its best value. The following day, the photocathode would be peaked up with Cs to its maximum value then overcesiated by $10 \%$. The same procedure was used for $\mathrm{Cs}$ and $\mathrm{Cs}+\mathrm{Li}$ activated cathodes. Gas exposure consisted of 30 minutes to background, 30 minutes at $1.5 \times 10^{-10}$ Torr of the dosing gas and 30 minutes at $5.0 \times 10^{-10}$ Torr of the dosing gas.

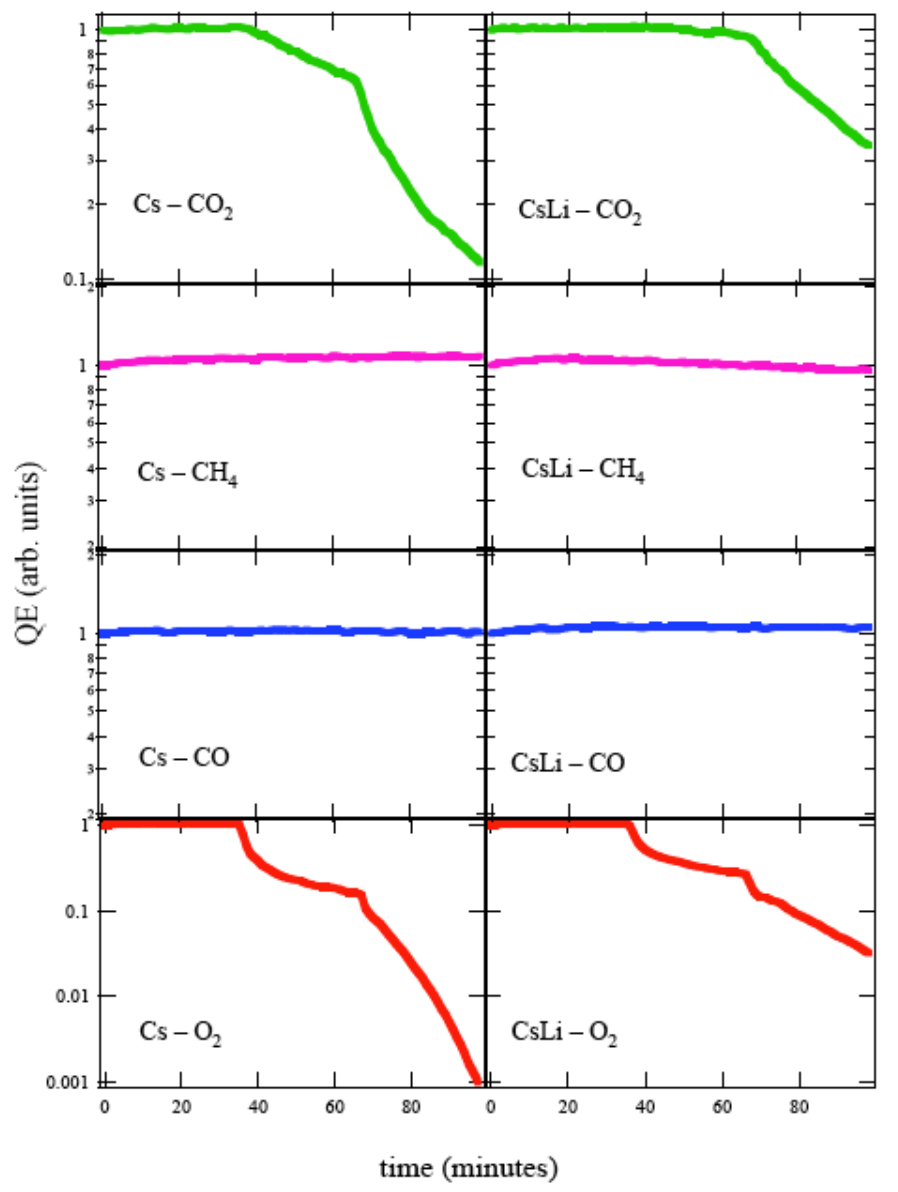

Figure 9. Summary plot of the results of gas dosing bulk GaAs activated with Cs only (left column) and Cs+Li (right column) for four different gasses, as noted in each plot. All vertical axes are log scale normalized to a starting value of unity. Each pair ( $\mathrm{Cs}$ and $\mathrm{Cs}+\mathrm{Li}$ ) use the same vertical scale for the indicated gas. Light source was HeNe laser, $\lambda=632.8 \mathrm{~nm}$.

Lifetime measurements were acquired under computer control. Between data points, the bias was electronically disconnected and the light source shuttered to inhibit dark current. An interesting phenomenon has been observed with respect to the $\mathrm{Cs}+\mathrm{Li}$ photocathode yield. After the overnight "rest", the recesiation always results in a yield somewhat greater than the maximum 


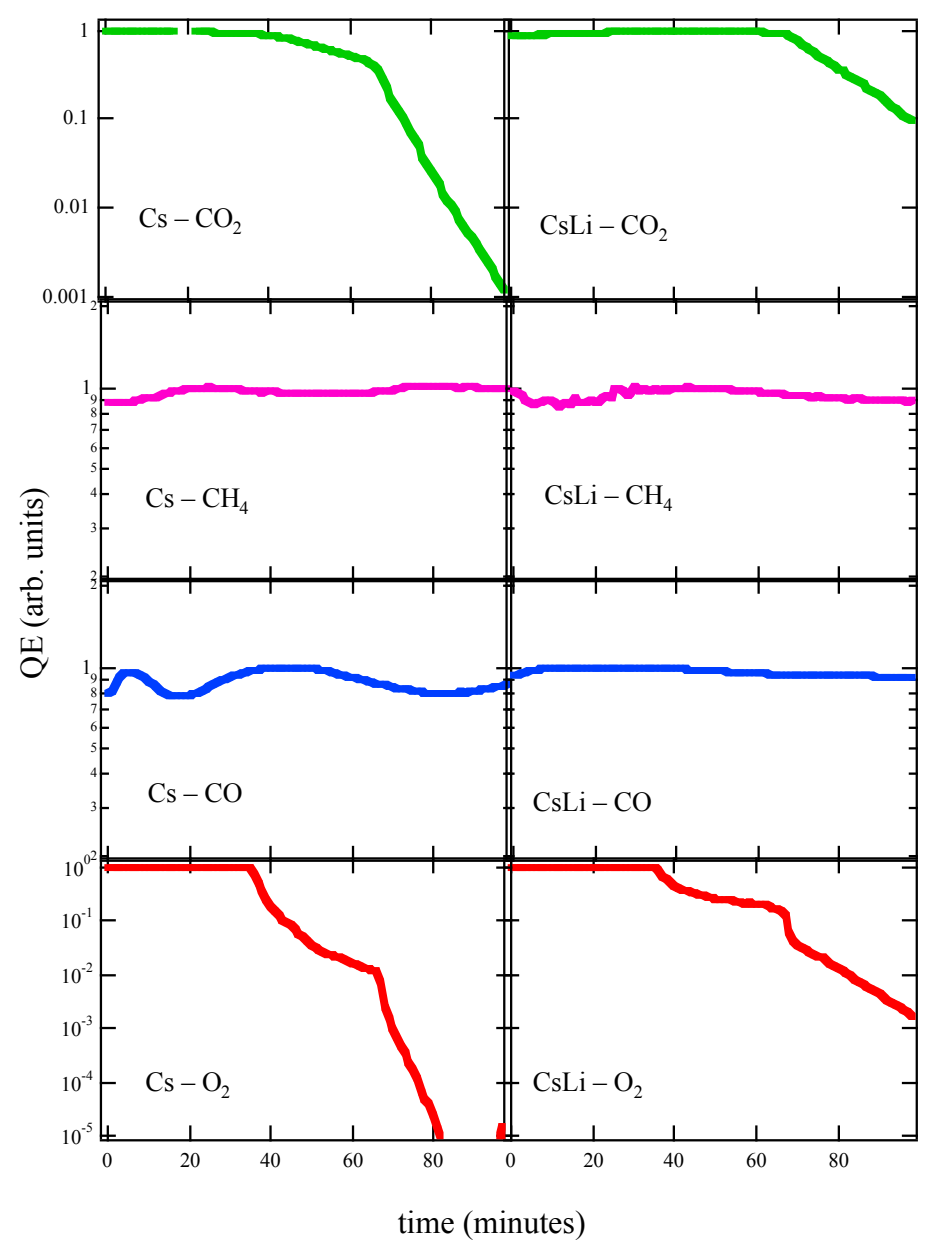

Figure 10. Summary plot of the results of gas dosing bulk GaAs activated with Cs only (left column) and $\mathrm{Cs}+\mathrm{Li}$ (right column) for four different gasses, as noted in each plot. All vertical axes are log scale normalized to a starting value of unity. Each pair ( $\mathrm{Cs}$ and $\mathrm{Cs}+\mathrm{Li}$ ) use the same vertical scale for the indicated gas. Light source was diode laser, $\lambda \sim 850 \mathrm{~nm}$.

achieved during the activation. The Cs activated samples always exhibit a small decrease over their activation maxima. Both effects are $\sim 5 \%$, but are measurable and repeatable. The summary plot data make clear that $\mathrm{CO}_{2}$ and $\mathrm{O}_{2}$ have strong effects (at $633 \mathrm{~nm}$ ) on the yield, while the $\mathrm{CH}_{4}$ and $\mathrm{CO}$ exposures (at $633 \mathrm{~nm}$ ) resulted in no significant drop in yield. These results are not entirely unexpected (at least for the Cs activated surfaces), and indicate that the Cs+Li activation does not result in an unintentionally sensitized surface for these other gas species. The $\mathrm{CO}_{2}$ data are similar to that reported in the Phase I results. The oxygen results, however, are both new and interesting. While not fully immunized to $\mathrm{O}_{2}$, the $\mathrm{Cs}+\mathrm{Li}$ activated photocathode maintained a 36 times greater yield at the end of the standard exposure schedule. 
Near bandgap measurements $(850 \mathrm{~nm})$ were conducted on bulk GaAs using the same activation schedule for the single and bi-alkali surfaces. The summary plot of these results are shown in fig. 10. The same plotting scheme as used for fig. 9 was employed. The diode laser employed for these measurements was neither power nor thermally stabilized. This can be seen in the middle two rows of plots and is the source of the short term drift in the normalized yield curves. There was no greater drop in the photoyield observed after $\mathrm{CO}$ and $\mathrm{CH}_{4}$ gas exposure than was observed during the first segment of background gas only exposure. The $\mathrm{CO}_{2}$ and $\mathrm{O}_{2}$ exposures both showed a stronger decay rate than was seen at $633 \mathrm{~nm}$ (fig. 9). However, the dual alkali activated surface maintained a 100x higher yield at the end of the $\mathrm{CO}_{2}$ exposure compared to the standard activated surface. The photocurrent during the $\mathrm{O}_{2}$ exposure reached the detection limit of signal to background for the method employed, so the data drops out at an exposure time of 80 minutes for the Cs only activated surface. Comparing at this time (rather than over the entire exposure period) with the bi-alkali activated surface, it also maintains the yield a factor of 100x greater than did the Cs only activated surface. While the overall numbers did show a decrease, the relative sensitivity to the active gasses $\left(\mathrm{CO}_{2}\right.$ and $\left.\mathrm{O}_{2}\right)$ was well diminished by the bi-alkali activation method.

\begin{tabular}{c}
$\frac{\text { GaAs } 100 \mathrm{~nm}}{\text { AlGaAs (30\%) } 1,000 \mathrm{~nm}}$ \\
\hline GaAs buffer $200 \mathrm{~nm}$ \\
\hline Substrate
\end{tabular}

(a)

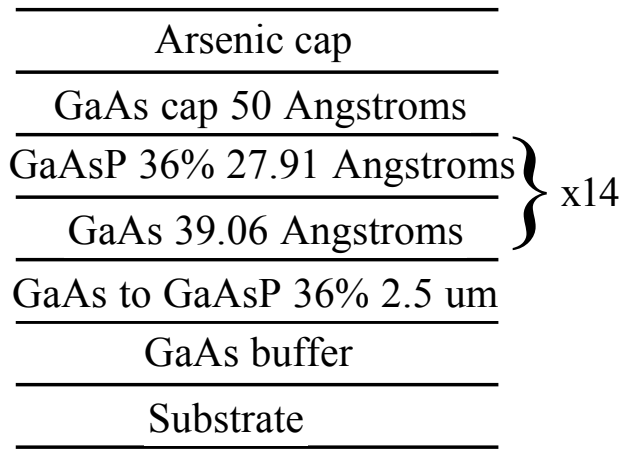

(b)

Figure 11. Structure of $100 \mathrm{~nm} \mathrm{MBE}$ grown GaAs[1] (a) and strained GaAs/ GaAsP superlattice sample[2] (b). Sample (a) was Be doped $1 \times 10^{19} / \mathrm{cm}^{3}$ throughout, while sample (b) was highly doped only in the GaAs cap layer so as to minimize depolarizing effects.

Two photocathode types were utilized in these series of measurements. The first was a $100 \mathrm{~nm}$ thin, unstrained GaAs grown atop an AlGaAs buffer layer and the second was a strained superlattice with periods of GaAsP/GaAs. The respective structures are shown in fig. 11. The same bi-alkali recipe as employed for bulk GaAs proved to be efficacious for the $100 \mathrm{~nm} \mathrm{MBE}$ material. As can be seen in fig. 12, the near bandgap yield for both the GaAs and AlGaAs bandgaps became sharper with the bi-alkali activation. This same effect was observed on bulk $\mathrm{GaAs}$ and indicates a surface barrier shape change due to the presence of both $\mathrm{Cs}$ and Li. For 
single alkali activated bulk GaAs, no shape change was seen irrespective of the alkali $(\mathrm{Cs}, \mathrm{Rb}, \mathrm{K}$, $\mathrm{Na}$ or Li) employed. As part of the overall alkali optimization procedure, yield curves were obtained for single alkali activations of bulk GaAs and are shown below in figure 13.

The change of material from bulk to MBE grown did not change the Cs only activated surface's reactivity (figure 14) with respect to near bandgap photoyield decay when compared to that for bulk GaAs measured at the same wavelength (figure 10) for any of the gasses utilized. Reaction to $\mathrm{O}_{2}$ was strongest, $\mathrm{CO}_{2}$ next in strength with $\mathrm{CO}$ and $\mathrm{CH}_{4}$ having no discernible effect on the yield for the dosing schedule employed. While still better protected than the Cs only surface, the MBE material did not show as strong a resistance to the active dosing gasses when the activation recipe for bulk GaAs was used. This indicates that a slightly higher concentration of $\mathrm{Li}$ is required for this material for best immunization. However, a higher Li concentration would reduce the starting yield (see discussion below) somewhat. The slightly higher reactivity of the MBE material could be due to several factors including a greater number of surface defects, though it is not likely they are due to the presence of step edges from the offset cut of the wafer to aid the MBE growth process (vicinally cut bulk GaAs did not show any higher reactivity than 'flat' GaAs in the Phase I work). While the dopants were different, zinc for the bulk GaAs and beryllium for the MBE grown material, their relative concentrations were low enough they are not likely candidates for reactivity modification. Additional insight comes from the study of the high polarization (also MBE grown) strained superlattice material as detailed below.

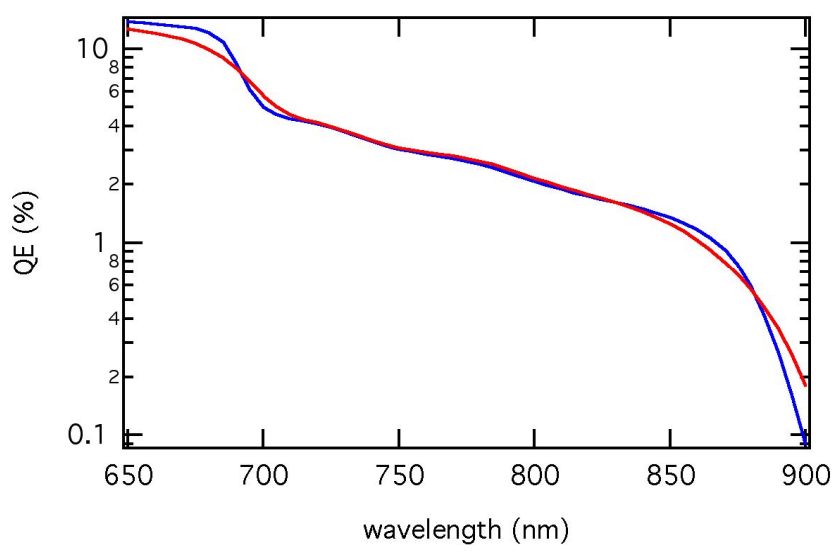

Figure 12. Quantum yield of $100 \mathrm{~nm}$ GaAs activated with Cs only (red) and Cs + Li (blue). As was the case for bulk GaAs, the photoyield curve shows a sharpening at the band gaps corresponding to that for GaAs $(\sim 870 \mathrm{~nm})$ and for the underlying AlGaAs ( 690 nm). 
DE-FG02-07ER84832

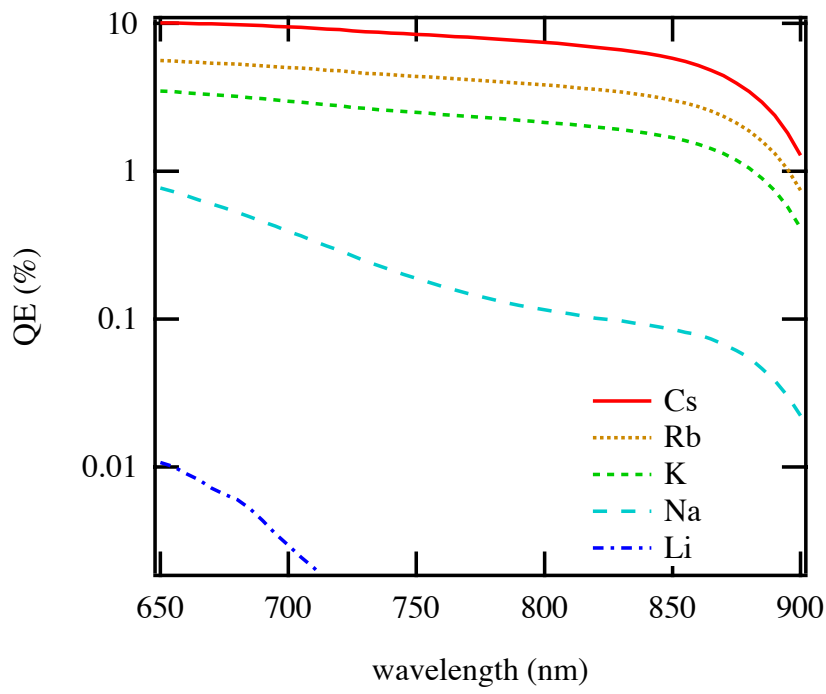

Figure 13. Quantum yield of bulk GaAs activated with single alkali, as noted, and $\mathrm{NF}_{3}$. Near bandgap regions are smooth in contrast to the data of figure 12. 


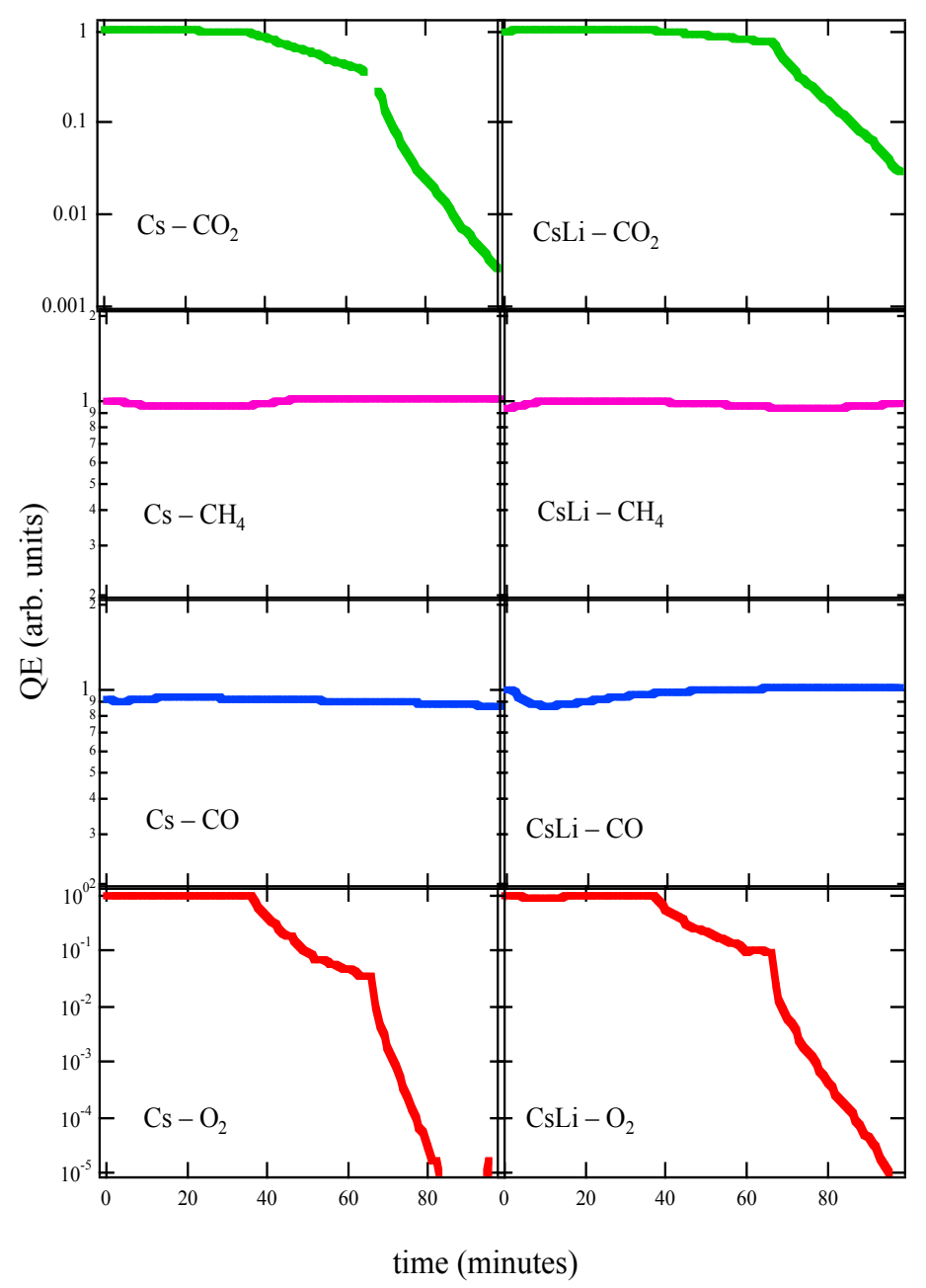

Figure 14. Summary plot of the results of gas dosing $100 \mathrm{~nm}$ thick MBE grown GaAs activated with $\mathrm{Cs}$ only (left column) and $\mathrm{Cs}+\mathrm{Li}$ (right column) for four different gasses, as noted in each plot. All vertical axes are log scale normalized to a starting value of unity. Each pair $(\mathrm{Cs}$ and $\mathrm{Cs}+\mathrm{Li})$ use the same vertical scale for the indicated gas. Light source was diode laser, $\lambda \sim 850 \mathrm{~nm}$.

The high polarization strained-superlattice material (see figure 11b) was grown with an arsenic cap atop it. The cap aids in easing preparation before use to a simple chemical clean, but has the disadvantage of a high pressure burst upon desorption of the arsenic in the initial heat cleaning stages. An additional complication is that the surface may retain an arsenic rich concentration after desorption[3] compared to III-V photoemitters grown without a final capping layer and the surface reconstruction can assume different character than for non-capped cathodes heat cleaned in a similar fashion. The final layer doping of the high polarization strained-superlattice material was comparable to that in the entire $100 \mathrm{~nm}$ thick MBE samples (figure 11a). 
DE-FG02-07ER84832

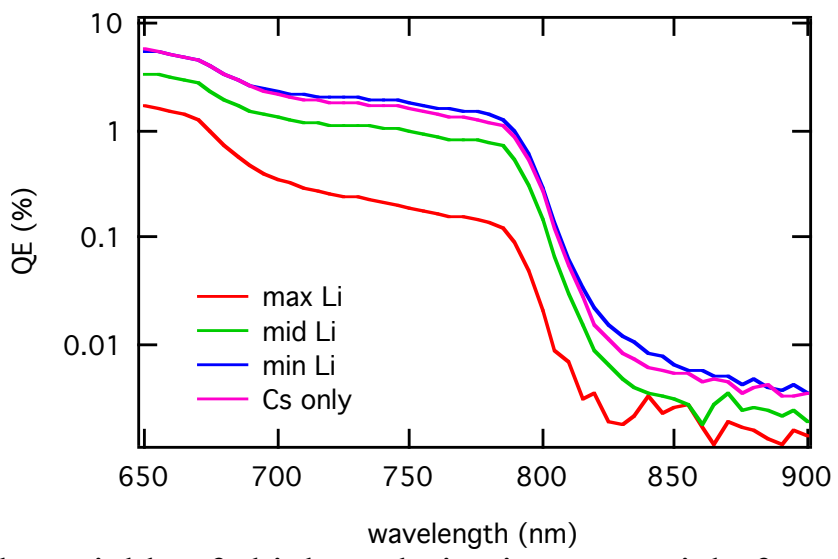

Figure 15. Photoyield of high polarization material for different relative contributions of Li during activation. The 'max Li' corresponds to the recipe used for bulk GaAs.

This material required a lower Li fraction during activation to maintain the yield at the same value as achieved with a Cs only activation. Figure 15 shows the photoyield for varying $\mathrm{Li}$ contributions during the bi-alkali activation. Only the lowest amount, about one half that for the maximum (standard) case maintained the yield at the Cs only value. Li concentration was also graded by ability to maintain the yield with $\mathrm{CO}_{2}$ gas exposure. Data are shown normalized (fig. 16) and absolute (fig. 17) below. The normalized data show that all Li activated surfaces achieved a greater immunity than the Cs only activated surface. The absolute data show that the 'max Li' activation only achieved utility at the longest times, while the two lower Li activations exceeded the performance of the Cs only activated surface once the higher dosing $\left(5 \times 10^{-10}\right.$ Torr $\mathrm{CO}_{2}$ ) began.

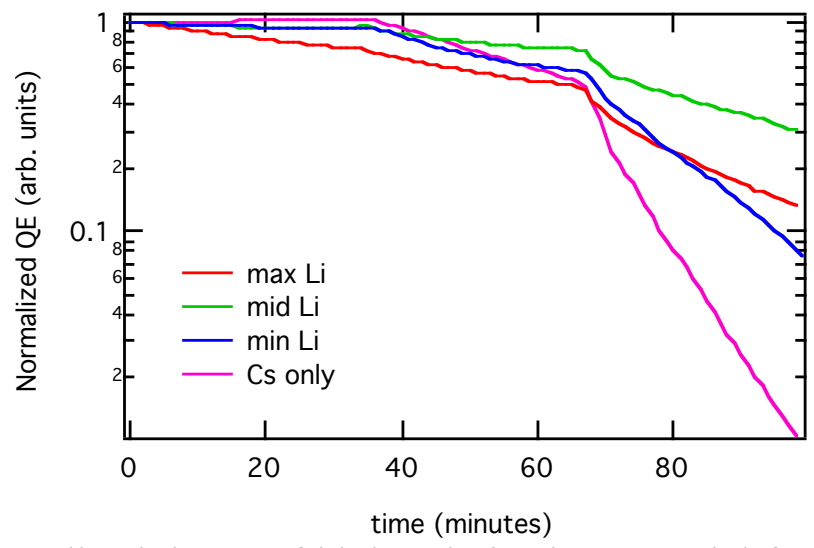

Figure. 16. Normalized decay of high polarization material for $\mathrm{CO}_{2}$ exposure $\lambda \sim$ $780 \mathrm{~nm}$. 
DE-FG02-07ER84832

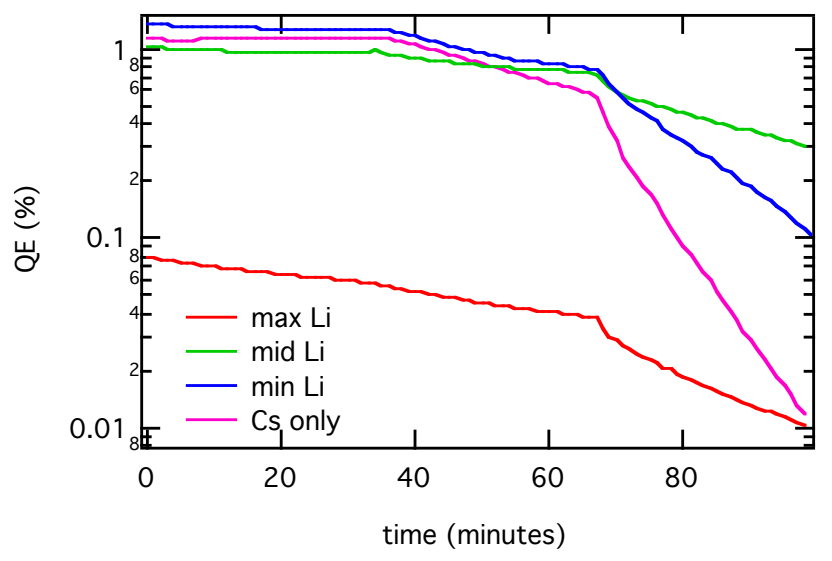

Figure. 17. Absolute decay of high polarization material for $\mathrm{CO}_{2}$ exposure $\lambda \sim 780$ $\mathrm{nm}$.

Gas dosing data for the high polarization material were taken using the 'min Li' activated material. Greater immunity can be had using the 'mid Li' dosing as seen in figure 15. However, there is a trade-off in initial photoyield. The summary plot of figure 18 therefore represents a lower bound on the immunization of this type of arsenic capped high polarization material. Even for the 'min $\mathrm{Li}$ ' recipe, the resistivity to $\mathrm{CO}_{2}$ exposure is much enhanced with the final yield about 10x that for the Cs alone activated surface. The $\mathrm{O}_{2}$ reactivity only improved marginally (again, better immunity is possible with some sacrifice in initial yield). The ordinarily nonreactive gasses did show some slight decay; it is not known at this time if this was due to build up of water vapor in the gas change manifold. Whatever the source, which may indeed better represent operational gas purity, the bi-alkali activated surfaces exhibited improved resistance. 
DE-FG02-07ER84832

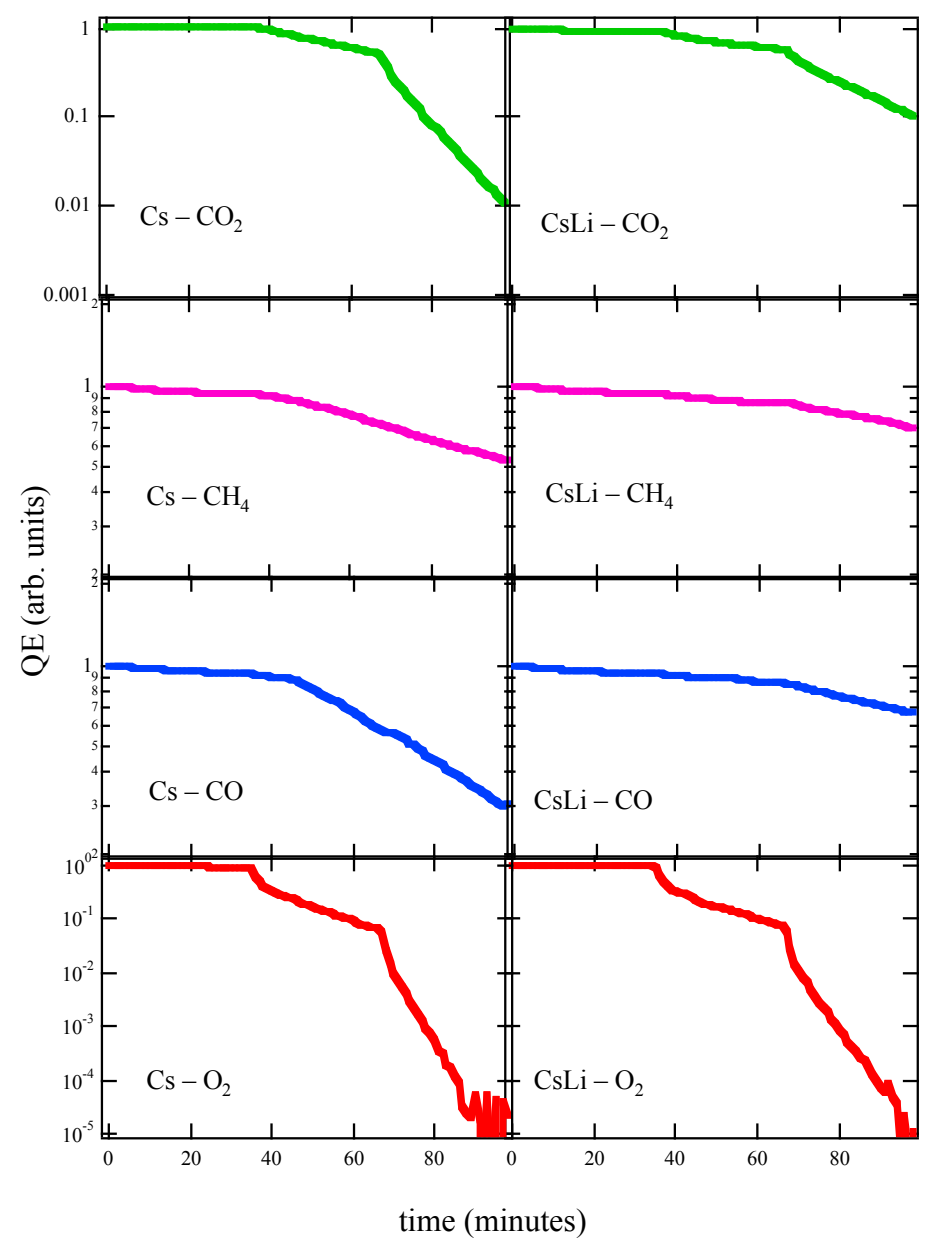

Figure 18. Summary plot of the results of gas dosing $100 \mathrm{~nm}$ thick MBE grown strained superlattice $\mathrm{GaAs} / \mathrm{GaAsP}$ high polarization cathodes activated with $\mathrm{Cs}$ only (left column) and $\mathrm{Cs}+\mathrm{Li}$ (right column) for four different gasses, as noted in each plot. All vertical axes are log scale normalized to a starting value of unity. Each pair (Cs and $\mathrm{Cs}+\mathrm{Li}$ ) use the same vertical scale for the indicated gas. Light source was diode laser, $\lambda \sim 780 \mathrm{~nm}$.

All the previous data were acquired using $\mathrm{NF}_{3}$ as the activation gas. To determine if the bi-alkali activation was effective when $\mathrm{O}_{2}$ was used, additional tests were conducted. The photoyield from $\mathrm{Cs}+\mathrm{O}_{2}$ activated $100 \mathrm{~nm}$ thick MBE grown GaAs did not differ significantly from that for Cs $+\mathrm{NF}_{3}$ activated GaAs. These yield data are shown below in figure 19. 
DE-FG02-07ER84832

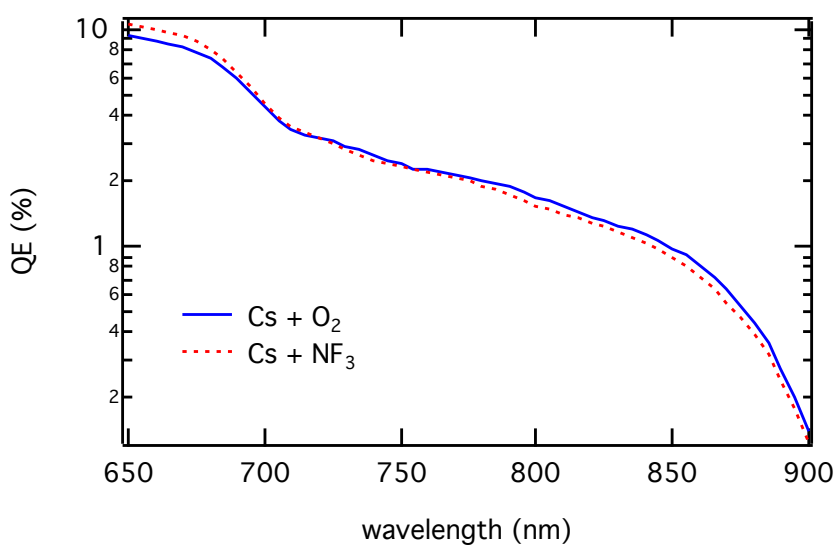

Figure 19. Quantum yield of $100 \mathrm{~nm}$ MBE grown GaAs for activations using Cs $+\mathrm{O}_{2}$ and $\mathrm{Cs}+\mathrm{NF}_{3}$. There is no significant difference in the yield curves.

Next, the effects of $\mathrm{CO}_{2}$ exposure on the standard, $\mathrm{Cs}+\mathrm{O}_{2}$ activated surface were compared with that for the $\mathrm{Cs}+\mathrm{Li}+\mathrm{O}_{2}$ activated surface with two different levels of $\mathrm{Li}$ coverage. These results are shown below in figure 20. It is clear that the immunization was not as good for the lower Li coverage ( 8 minutes initial on time) as it was for the higher coverage (12 minutes initial on time).

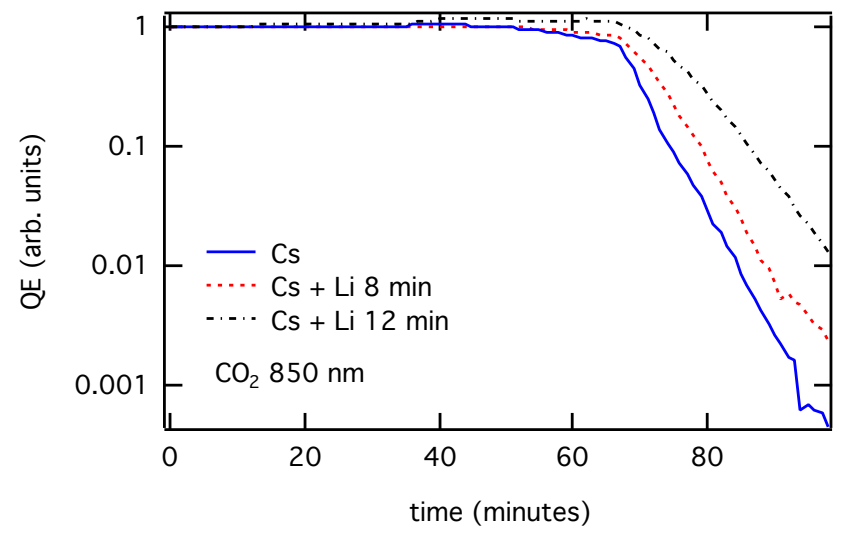

Figure 20. Quantum yield decay as a function of time for $100 \mathrm{~nm} \mathrm{MBE}$ grown GaAs upon exposure to $\mathrm{CO}_{2}$. All activations used $\mathrm{O}_{2}$ as the oxidizer. The three cases shown are for $\mathrm{Cs}$ only, $\mathrm{Cs}+\mathrm{Li}$ with an initial $\mathrm{Li}$ dose of 8 minutes and $\mathrm{Cs}+\mathrm{Li}$ with an initial Li dose of 12 minutes. The yield data were normalized at $\mathrm{t}=0$.

The absolute yields did not suffer with the greater Li-to-Cs ratio. The yields at $633 \mathrm{~nm}$ for the three cases at the time of activation were $9.3 \%, 10.1 \%$ and , 9.0\% respectively. This is a normal spread for activations of the same type. The $\mathrm{CO}_{2}$ exposure schedule was the standard recipe: 30 minutes of background gas only, 30 minutes of $1.5 \times 10^{-10}$ Torr $\mathrm{CO}_{2}$ and then 30 minutes of 
5.0x $10^{-10}$ Torr $\mathrm{CO}_{2}$. All surfaces showed little response to the low pressure $\mathrm{CO}_{2}$ and a slow onset for the higher pressure. However, the $\mathrm{Cs}+\mathrm{Li}+\mathrm{O}_{2}$ activated surface for long exposure times was more than one order of magnitude more resistant to the $\mathrm{CO}_{2}$ exposure than the standard, $\mathrm{Cs}+\mathrm{O}_{2}$ activated surface. Interestingly, the activated surfaces seem to be somewhat more resistant to the initial, lower pressure $\mathrm{CO}_{2}$ exposure than the $\mathrm{NF}_{3}$ activated surfaces, though not more so than the $\mathrm{NF}_{3}$ activated surfaces for the long exposures.

\section{Measure electron spin-polarization of bi-alkali activated photoemitters}

To verify that the $\mathrm{Cs}+\mathrm{Li}$ activations performed at SLAC had the same character as those performed at Saxet, $\mathrm{CO}_{2}$ dosing was performed on representative photocathodes. Normalized yield dosing data are shown below in figures 21 and 22 for $100 \mathrm{~nm} \mathrm{MBE}$ grown GaAs and highpolarization strained superlattice material, respectively. As was seen at Saxet, the activated surface including $\mathrm{Li}$ evinces a greater resilience with respect to $\mathrm{CO}_{2}$ exposure than the Cs only activated surface. The relative changes are dependent on the actual activation recipe and gas dosing pressures, and while close to the Saxet results, do show some difference with respect to the relative change at the completion of dosing. Overall, however, the results are in keeping with the beneficial effects of $\mathrm{Li}$ in the activation process.

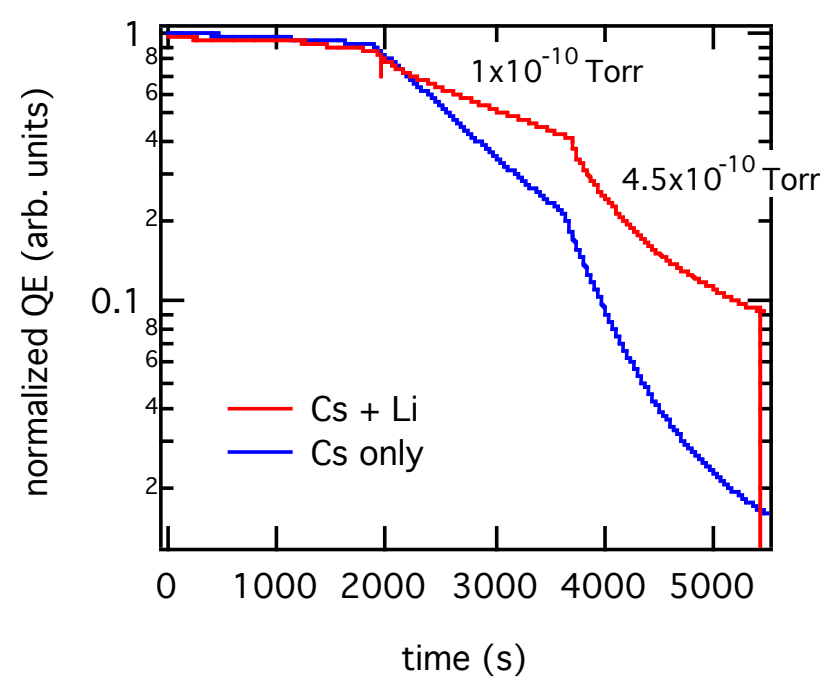

Figure 21. $\mathrm{CO}_{2}$ yield effect as a function of time as measured at SLAC for the 100 nm MBE grown GaAs.

To simplify the interpretation of the results, only the $100 \mathrm{~nm}$ MBE grown GaAs and high polarization type materials had their wavelength dependent electron spin-polarizations measured. The reason for this is that in bulk GaAs, the polarization is much more sensitive to the value of the photoyield. This means that any change in polarization would be difficult to isolate between the modified yield due to the $\mathrm{Cs}+\mathrm{Li}$ activation and any effect the presence of $\mathrm{Li}$ would have on 
the polarization outside of the aforementioned yield change. For both the $100 \mathrm{~nm}$ MBE grown GaAs and the high polarization strained superlattice material, the photoelectron polarization has only a weak dependence on the photoyield, so any effects due to the use of $\mathrm{Li}$, if present, are much easier to see.

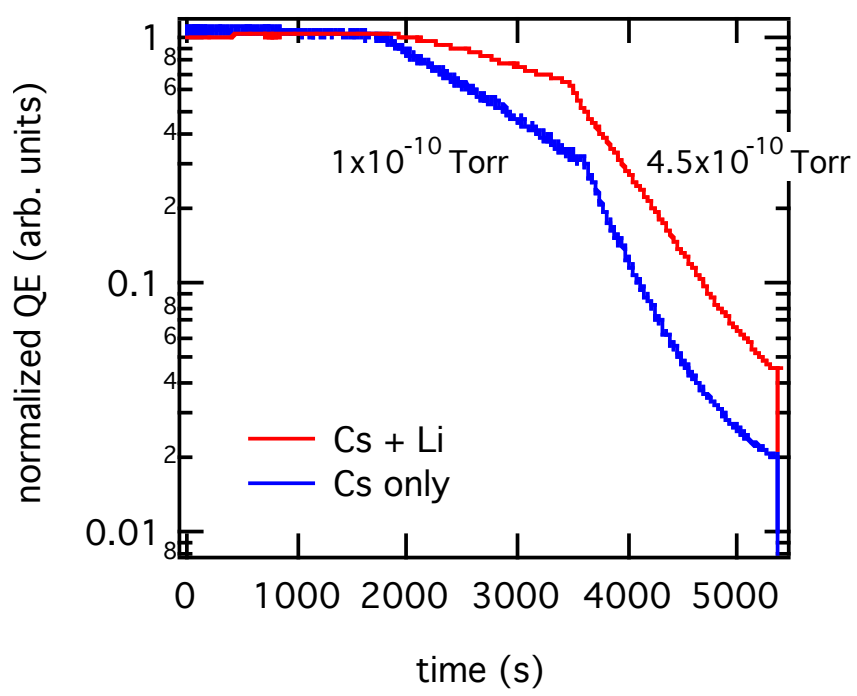

Figure 22. $\mathrm{CO}_{2}$ yield effect as a function of time as measured at SLAC for the high polarization material.

Data for the $100 \mathrm{~nm} \mathrm{MBE}$ grown GaAs are shown below in figure 23 for Cs and Cs+Li activated surfaces. The electron polarization as a function of wavelength shows typical behavior for this material. Within experimental error, the polarization as measured from each type of activated surface, is the same. This is a very important result! Not only can we immunize the surface against some level of exposure to background gasses, but we can do so without hurting the photoelectron spin-polarization. This clears the method for use in those applications requiring the highest electron polarization.

Similar results were obtained for measurements on the high polarization material as seen in figure 24. As for the $100 \mathrm{~nm}$ MBE grown material, the higher concentration Li activation recipe was used to enhance any potential $\mathrm{Li}$ effects. This is the reason for the somewhat lower yield than for the Cs only case. However, the polarization curves are once again equal within experimental error. These data again show that the immunization activation recipe can be used without any detrimental effects on the photoelectron spin-polarization. 
DE-FG02-07ER84832

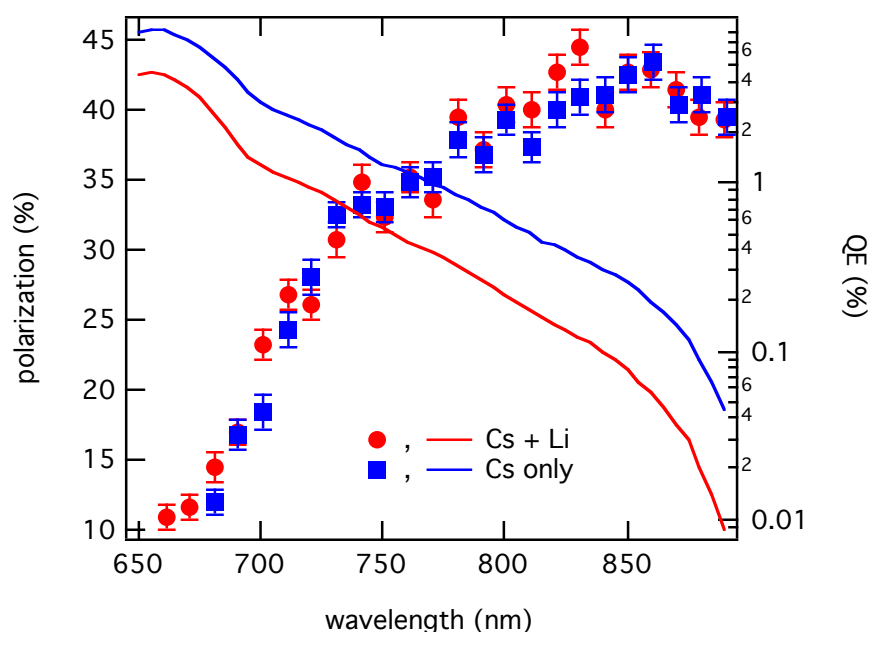

Figure 23. Polarization and photoyield as function of wavelength for $100 \mathrm{~nm}$ thick MBE grown GaAs. Shown are data from Cs only activated and $\mathrm{Cs}+\mathrm{Li}$ activated surfaces. This was a high Li content activation.

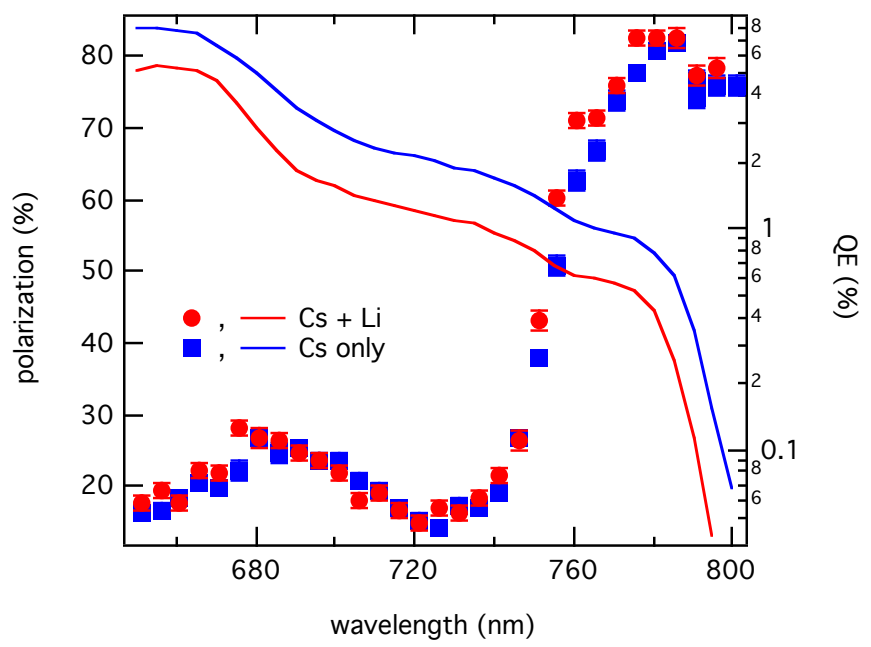

Figure 24. Polarization and photoyield as function of wavelength for high polarization strained superlattice photocathode (SVT 5387). Shown are data from $\mathrm{Cs}$ only activated and $\mathrm{Cs}+\mathrm{Li}$ activated surfaces. This was a high Li content activation, hence the diminished photoyield.

\section{Photoemission characterization of $\mathrm{Cs}+\mathrm{Li}$ activated surfaces}

Preparation of the end station chamber (figure 25) on beamline 8-1 at SSRL included installation of $\mathrm{Cs}$ and $\mathrm{Li}$ channel sources as well as the $\mathrm{NF}_{3}$ gas source required for activation. Preliminary activation tests were performed on bulk GaAs. Additional activation tests using $\mathrm{Cs}+\mathrm{Li}$ and 100 
nm MBE grown GaAs were also performed. An optical spectrometer assembly was made available so that the activated photocathodes could be characterized for photoyield as a function of wavelength.

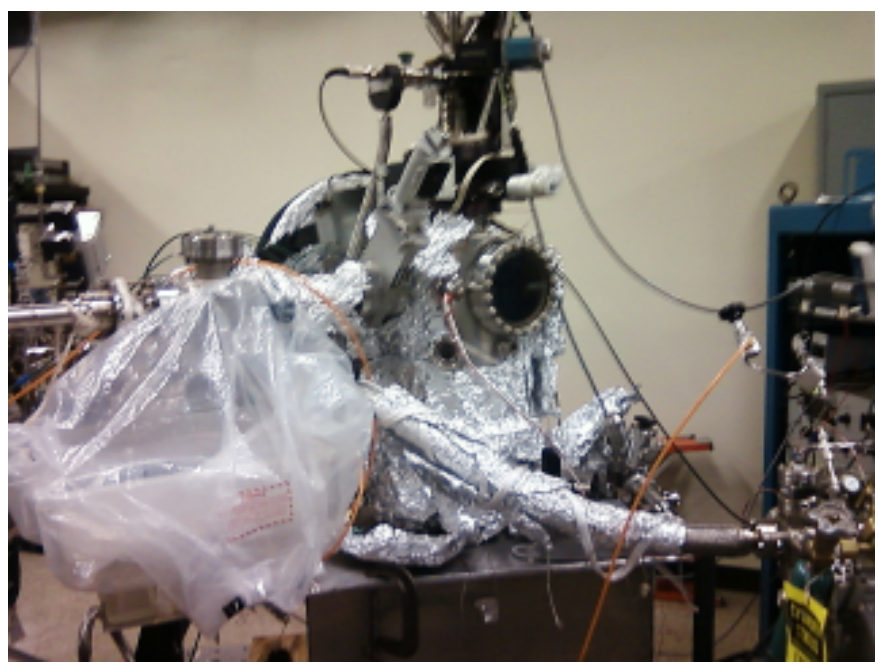

Figure 25. End station chamber at SSRL. Samples are inserted into the loadlock using the portable nitrogen glove bag (left). Behind the chamber is just visible the PHI hemispherical energy analyzer

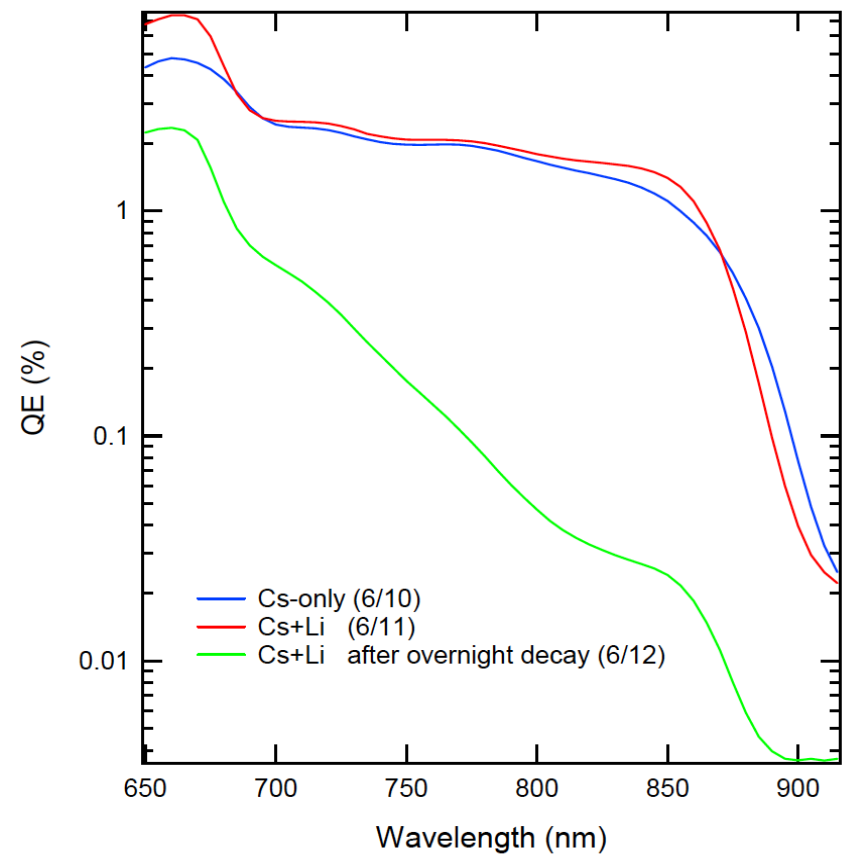

Figure 26. Quantum yield of $100 \mathrm{~nm}$ MBE GaAs taken in the SSRL endstation. Consistency with the previous work was established by activating the $100 \mathrm{~nm}$ MBE grown GaAs 
in the end station and taking scans of photoyield over several days. One such set of data are shown in figure 26. The shape of the photoyield curve is consistent with that seen in data taken earlier at Saxet and SLAC: the yield curve for the Cs + Li activation shows sharp knees at the GaAs and AlGaAs band gaps compared to the curve generated from the Cs only activated sample.

Photoemission spectra were collected by an end station equipped with a PHI hemispherical electron energy analyzer at beamline 8-1 (hv: 30-170 eV) and beamline 10-1 (hv: 200-1000 eV) of SSRL. All data were normalized to incoming photon beam flux. The F 1s, N 1s and Cs 4d spectra for the $\mathrm{Cs}+\mathrm{Li}+\mathrm{NF}_{3}$ activated sample are shown in figure 27(a), 27(c) and 27(d), respectively with valence band data appearing in figure $27(\mathrm{~b})$. Spectra for a $\mathrm{Cs}+\mathrm{NF}_{3}$ activated sample are shown in the same plot for comparison and contrast.

The peak positions of $\mathrm{F} 1 \mathrm{~s}$ and $\mathrm{N} 1 \mathrm{~s}$ are notably different from $\mathrm{Cs}+\mathrm{NF}_{3}$ activated samples, with the F 1s peak moving toward lower kinetic energy (higher binding energy) by $1.00 \pm 0.2 \mathrm{eV}$ and $\mathrm{N}$ 1s moving toward higher kinetic energy (lower binding energy) by $0.30 \pm 0.1 \mathrm{eV}$. The peak shifts indicate that the presence of Li changes the charge distribution of the N-F cluster, making $\mathrm{N}$ more electronegative and $\mathrm{F}$ more electropositive. The change in the $\mathrm{F}$ binding energy can also be seen in the valence band region plotted in Fig. 27(b), where the peak related to the F $2 p$ level shifts toward lower kinetic energy for $\mathrm{Cs}+\mathrm{Li}+\mathrm{NF}_{3}$ activated samples.
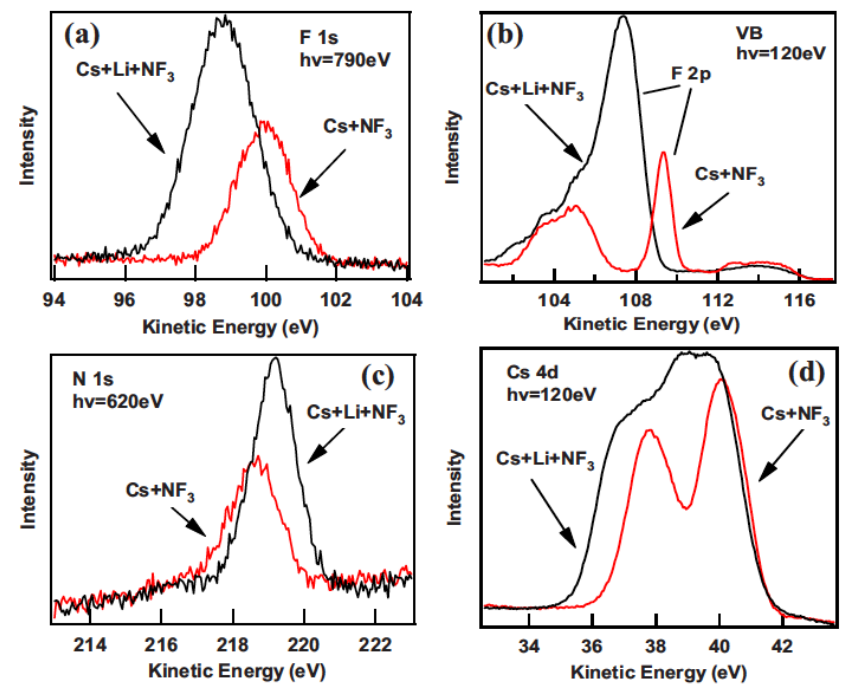

Figure 27. (a) F 1s, (b) valence band, (c) N 1s and (d) Cs 4d spectra for GaAs photocathodes activated by $\mathrm{Cs}+\mathrm{NF}_{3}$ and $\mathrm{Cs}+\mathrm{Li}+\mathrm{NF}_{3}$. F $2 \mathrm{p}$ feature is labeled in (b).

By taking photoemission at two angles (normal and $60^{\circ}$ off normal), depth dependent information can be accessed. Such data were acquired for the $\mathrm{Cs} 4 \mathrm{~d}$ and the $\mathrm{Li} 1 \mathrm{~s}$ core levels. 
Both exhibited distinct pairs of lines with chemical shifts of $1.2 \pm 0.1 \mathrm{eV}$ and $1.7 \pm 0.2 \mathrm{eV}$, for Cs and $\mathrm{Li}$, respectively. These shifts are due to the different chemical environments in which the atoms reside, i.e., each set corresponds to different numbers or types of nearest neighbor atoms (or the lack thereof). Relative intensity differences are also apparent in the line-analyzed spectra. The layered activation structure components as determined by these XPS measurements is shown below in figure 28. The Li atoms appear both atop the GaAs and possibly sub-surface. The Cs atoms form a double layer with the intact $\mathrm{NF}_{3}$ molecule sandwiched between the layers.

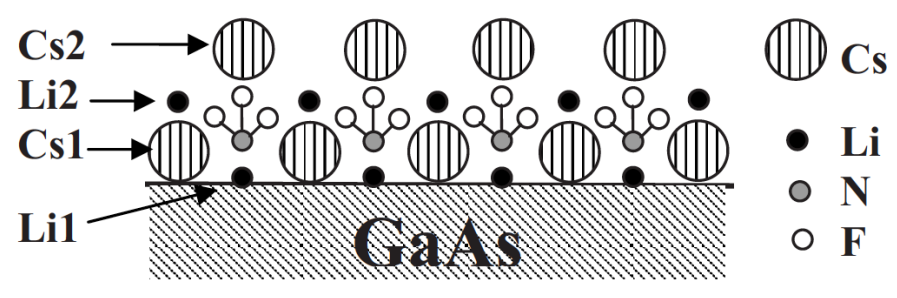

Figure 28. Structure of bi-alkali activation layer on GaAs obtained from XPS data analysis.

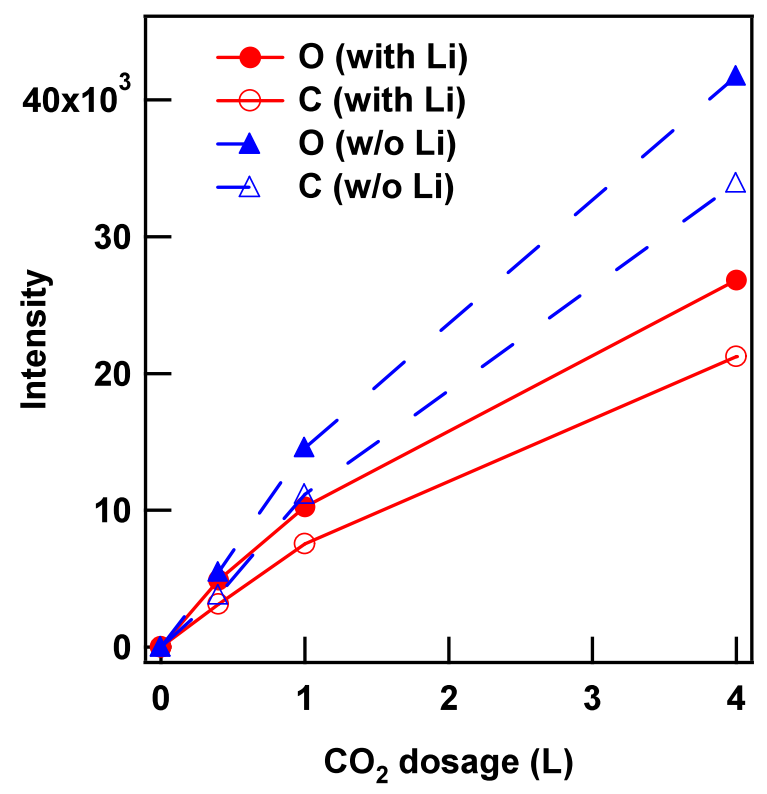

Figure 29. Photoelectron intensity of $\mathrm{C}$ and $\mathrm{O}$ peaks as function of exposure to $\mathrm{CO}_{2}$ for $\mathrm{Cs}$ and $\mathrm{Cs}+\mathrm{Li}$ activated GaAs.

The details of the resistance to $\mathrm{CO}_{2}$ were also studied via XPS. By measuring the relative intensity of the $\mathrm{C} 1 \mathrm{~s}$ and $\mathrm{O} 1 \mathrm{~s}$ lines as a function of $\mathrm{CO}_{2}$ exposure, the uptake rate for the bi- 
alkali activated surface and the standard surface can be compared. As shown in figure 29, the atomic constituents of $\mathrm{CO}_{2}$ have a lower uptake rate for the bi-alkali activated surface. This answers part of the question as to why the surface is more immune to $\mathrm{CO} 2$; it absorbs at a slower rate. However, exactly why this is the case is still an outstanding question.

\section{Growth and testing of a-Si on GaAs as robust emitter layer}

The bandgap of amorphous silicon can be shifted by the addition of germanium which results in the growth of a silicon-germanium alloy. The germanium source is the growth gas germane $\left(\mathrm{GeH}_{4}\right)$. For the data shown below in figure 30, the near mobility edge shift of $40 \mathrm{~nm}$ was achieved by the addition of the germane as a $25 \%$ fraction of the active growth gas components. This is an incredibly easy way to tailor photocathode wavelength response to either a drive laser system or a signal source when used as part of a photodetection or light amplification device.

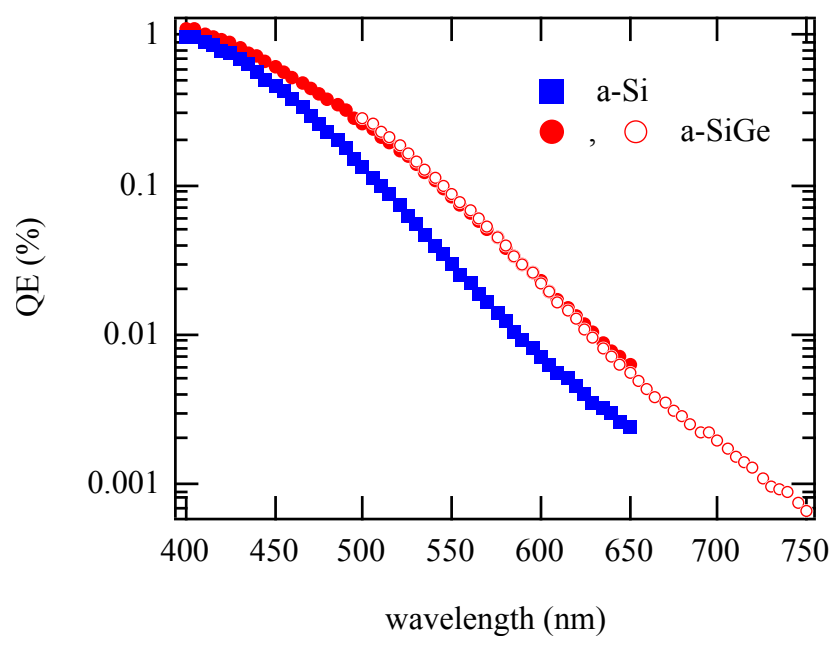

Figure 30. Comparison of amorphous silicon and first-growth of amorphous SiGe using a $25 \%$ germane growth gas component. The data were taken in two wavelength segments for the a-SiGe sample.

For the data shown in figure 31 , the near mobility edge shift of $\sim 140 \mathrm{~nm}$ was achieved by the addition of the germane as a $60 \%$ fraction of the active growth gas components, with the balance silane. Growth optimization indicates that the best a-SiGe films require the same conditions as that for a-Si. 


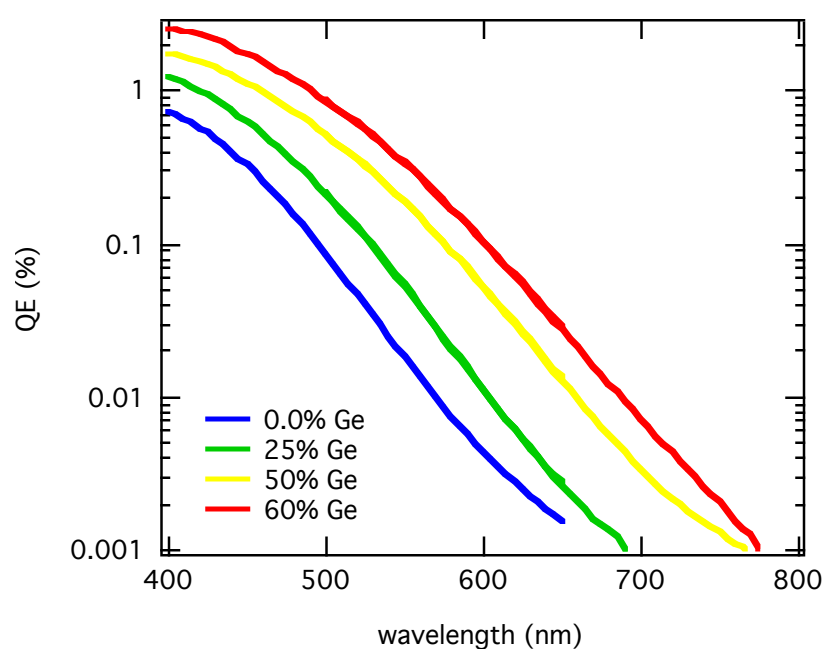

Figure 31. Yield as a function of Ge concentration. Samples were activated twice on separate days.

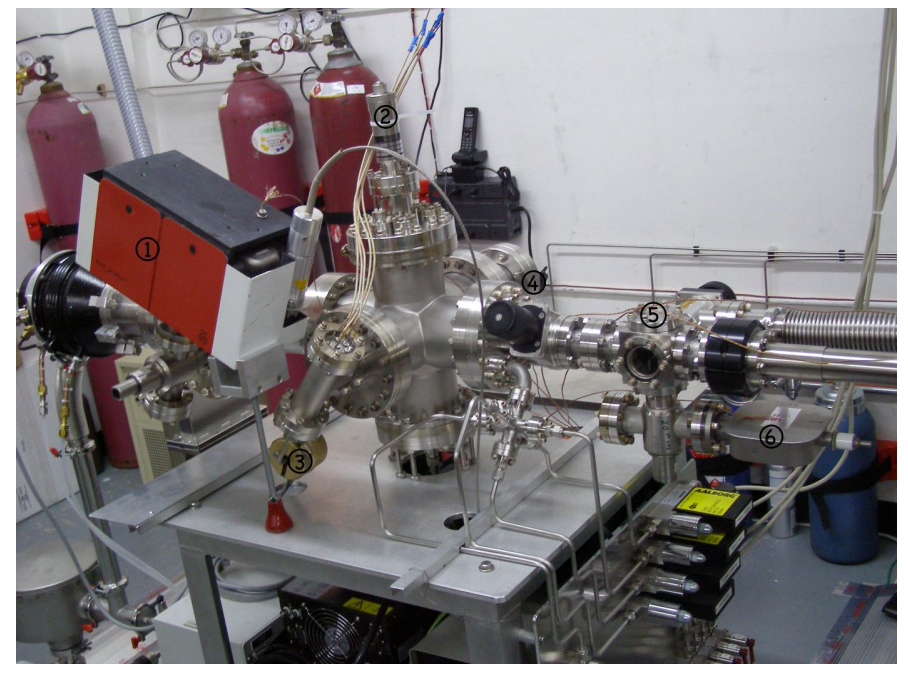

Figure 32. Modified RF PECVD system prior to bakeout. Changes, as numbered, were: 1 . Addition of $40 \mathrm{l} / \mathrm{s}$ holding ion pump and right angle metal seal valve, 2. High temperature and UHV compliant sample holder/transfer unit, 3. Bakeable baratron pressure gauge, 4. Bakeable gate valve, 5. Bakeable (grease free) loadlock introduction chamber and 6. Ion pump (8 liter/s, shown without magnet) and associated metal seal valve on load chamber.

To undertake high quality growth on GaAs substrates, several modifications to the growth system were required. And while straightforward, they were numerous. The overall goal was to make the system capable of heat cleaning the GaAs substrate (photogenerating layer) before the deposition of the amorphous silicon (photoemitting layer). An additional improvement included 
the upgrade of the load system to decrease the amount of unintentional water vapor that could migrate into the growth chamber during sample loading/unloading. The main structural changes are noted in figure 32, though the details of the modified sample heating station are not visible from the exterior of the chamber.

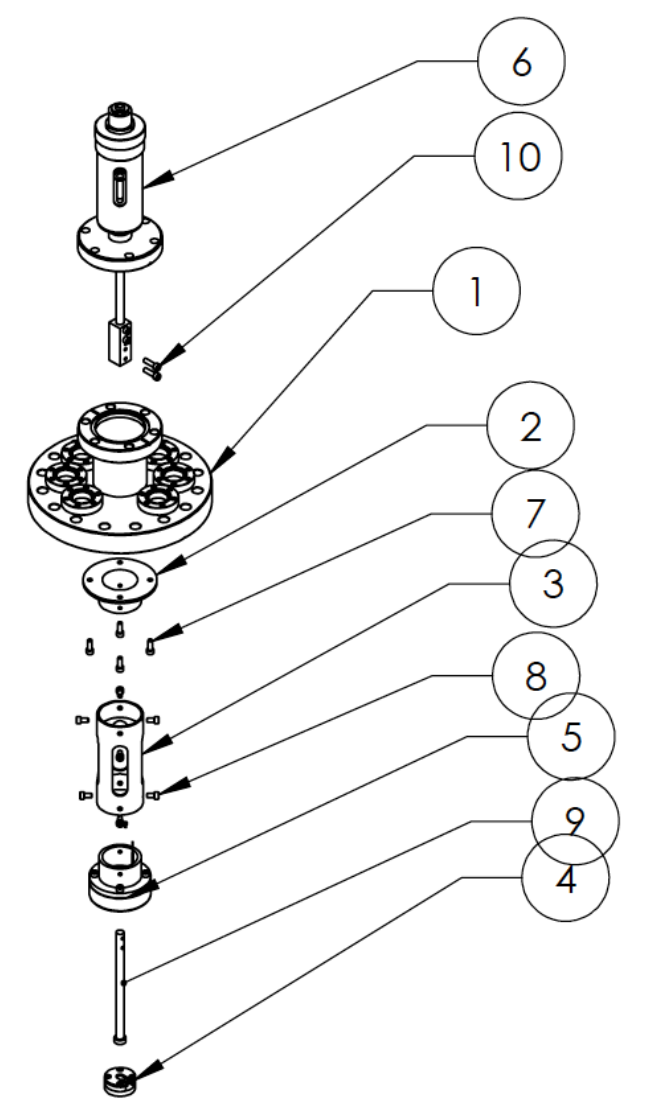

Figure 33. Exploded view diagram of the upgraded sample holder/heater. The modifications necessary to make the unit high temperature compatible included: Sample holder (4) made from molybdenum, sample holder rod (9) made from titanium, heater surround (5) made from titanium but for a molybdenum insert at the bottom, linear drive (6) changed for bakeable unit and the slotting of the support tube (3) to make the egress of the heater and thermocouple wires (not shown) simpler.

In order to grow amorphous silicon (a-Si) on oxide-free GaAs, it is necessary to clean in situ the GaAs substrate. This follows the standard chemical clean before installation into the load chamber. To minimize the amount of re-oxidation that occurs during the cool down phase of the cleaning cycle, the sample holder/heater and other elements of the growth system were changed to allow the bakeout of the chamber, permit the heat cleaning temperature to be reached and 
achieve efficient pumping of gas from the heated parts. So as to minimize the gas load generated upon heat cleaning the GaAs substrate, the system now has a holding ion pump which gets valved out during the growth phase of the process. The turbo and backing pump employed for the growth is ordinarily shut down when not in use. The holding pump permits the system vacuum to be maintained and for the sample to be heat cleaned while diminishing the likelihood of oxidizer (water vapor) migration via the turbo pump system. Improvements in the sample holder/heater are detailed in figure 33. The materials making up the unit were changed to make heat transfer most efficient to the sample and least efficient to the rest of the unit. For the temperature required, $\sim 550^{\circ} \mathrm{C}$, the sample mount was changed from aluminum to molybdenum, with all nearby parts made from titanium to take advantage of its poor thermal conductivity, but high temperature reliability.

One exception is a molybdenum insert in the heater surround. This part contacts the sample holder and using molybdenum here improves the thermal conductivity to the sample. Except as noted, the sample holder/heater remains the same as the one used for previous a-Si growth. Over 200 samples were fabricated with the old unit without any failures. The heater unit was calibrated with a second thermocouple installed in the sample position. Data from the calibration appears below in figure 34. The heater (HeatWave Labs. Inc.) readily achieved the necessary temperature for GaAs thermal cleaning.

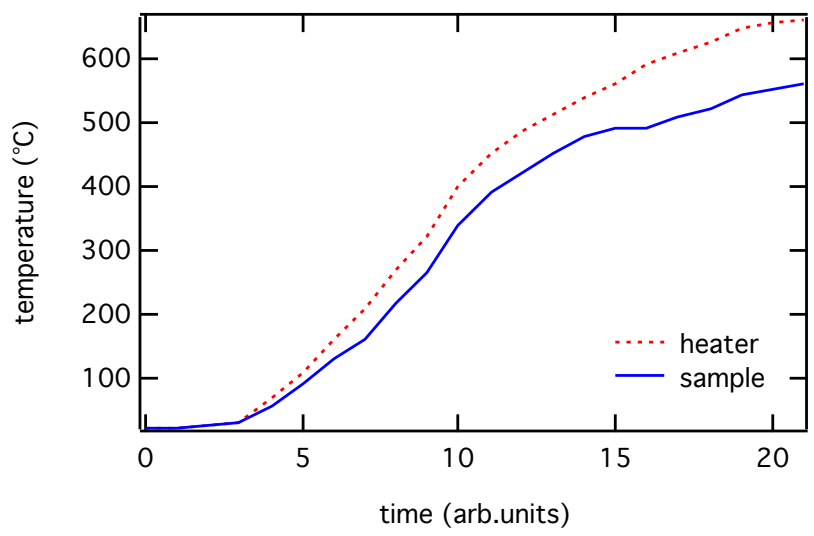

Figure 34. Calibration of heater unit. The heater thermocouple was directly in contact with the heater surround via an 0-80 screw. The sample temperature was measured by the temporary installation of a second thermocouple feedthrough with the junction spot welded to the top (discharge facing) surface of a standard tantalum foil substrate. At the GaAs heat cleaning temperature, there was a $100^{\circ} \mathrm{C}$ difference in the heater and sample temperatures.

Preliminary tests were performed on chemically cleaned GaAs substrates with overlayers deposited at the a-SiGe optimal-for-growth $180^{\circ} \mathrm{C}$. These tests were needed before proceeding to 
ones in which the substrate started clean from a high temperature in situ cleaning.

Thick films

Amorphous silicon (germanium) films, $\sim 100 \mathrm{~nm}$ thick were grown atop GaAs substrates (bulk GaAs, $25 \mathrm{~V}$ anodized, degreased and $\mathrm{NH}_{4} \mathrm{OH}$ stripped, same as for when used as a photocathode) to determine the quality of film adhesion and influence of the substrate on the a-Si film's properties, either by morphology, element diffusion or direct surface deposition during the a-Si cleaning process, a 1-1/2 minute $2 \%$ HF dip followed by 2 minutes DI water rinse. For comparison, the photoyield from an a-Si film grown immediately prior to the first test on the standard tantalum substrate is shown together below with the photoyield from one grown on a GaAs substrate. From these data, figure 35, it is evident that there are no deleterious effects from the use of a GaAs substrate for the thick film. However, from these data it is not possible to rule out any short range diffusion that might affect thinner films.

An analogous set of data was acquired for $\mathrm{a}-\mathrm{Si}_{0.4} \mathrm{Ge}_{0.6}$ films on $\mathrm{GaAs}$ and $\mathrm{Ta}$ substrates. This material has a nominally smaller band gap $\left(\mathrm{E}_{\mathrm{g}} \sim 1 \mathrm{eV}\right.$ at $\left.300 \mathrm{~K}\right)$ than GaAs. Due to limitations on modeling such thin films, optical analysis from transmission data of the a-Si $\mathrm{i}_{0.4} \mathrm{Ge}_{0.6}$ films grown on transparent substrates could best quantify the band gap as $<1.4 \mathrm{eV}$. These data are shown in figure 36. Again, no difference that cannot be attributed to usual sample variations was observed.

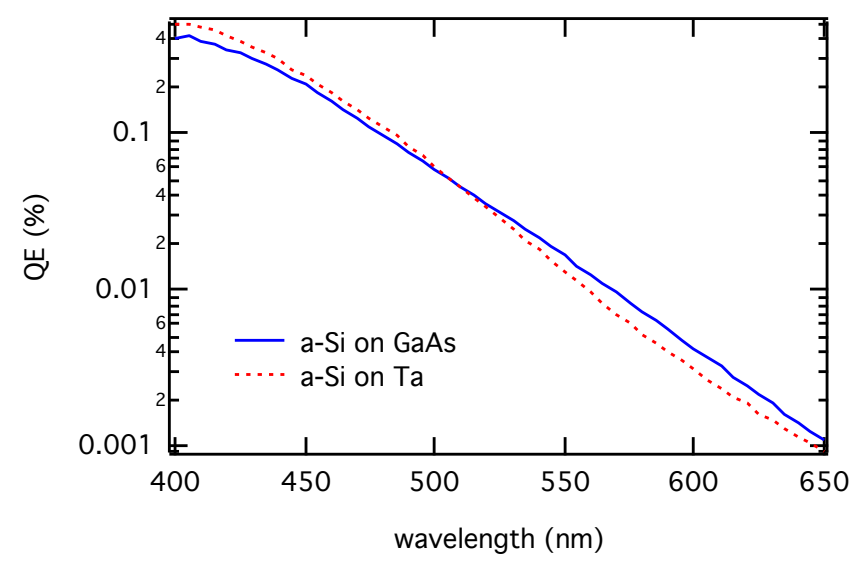

Figure 35. Photoyield from $100 \mathrm{~nm}$ a-Si films grown on GaAs and Ta substrates. The difference in yield is of the same order as that seen due to normal growth-togrowth variation. 


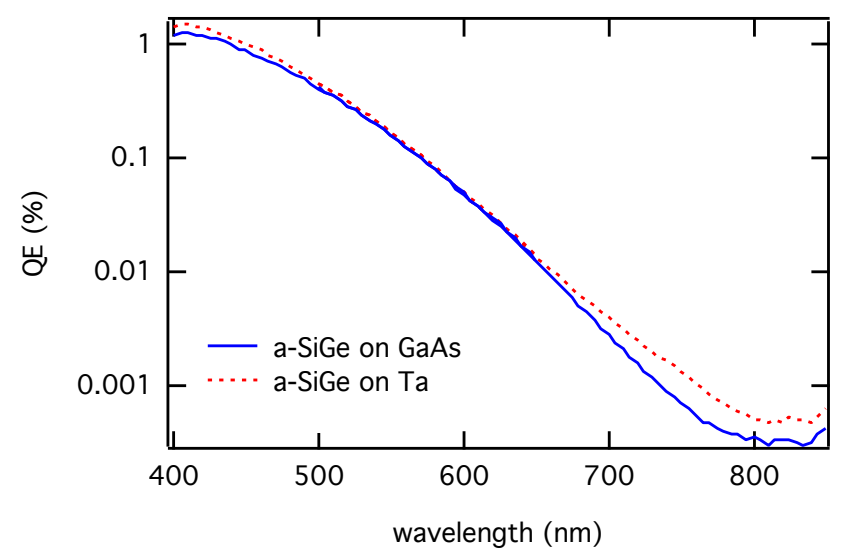

Figure 36. Photoyield from $100 \mathrm{~nm}$ a-Si $\mathrm{Si}_{0.4} \mathrm{Ge}_{0.6}$ films grown on $\mathrm{GaAs}$ and $\mathrm{Ta}$ substrates. The difference in yield is of the same range as that seen due to normal growth-to-growth variation. Note the change in horizontal scale from figure 35 .

$\underline{\text { Thin films }}$

Amorphous silicon germanium films of various thicknesses were grown atop bulk GaAs. The substrates were only chemically cleaned before insertion and only heated to the nominal growth temperature, $180^{\circ} \mathrm{C}$. Therefore, it is expected that the interface between the GaAs and the a-SiGe film consisted of a thin, oxidized layer of GaAs. Successively thinner layers of a-SiGe (p-type, boron doped) were grown atop several GaAs substrates in this manner. A composite plot of the results are shown below in figure 37. Included in the plot are data from a hydrogen plasma treated GaAs substrate without any film and photoyield data from a GaAs sample that had not been through the growth system, but was installed into the a-Si photocathode test chamber and heat cleaned in the normal fashion for GaAs, i.e., at at temperature of $550^{\circ} \mathrm{C}$ for one hour.

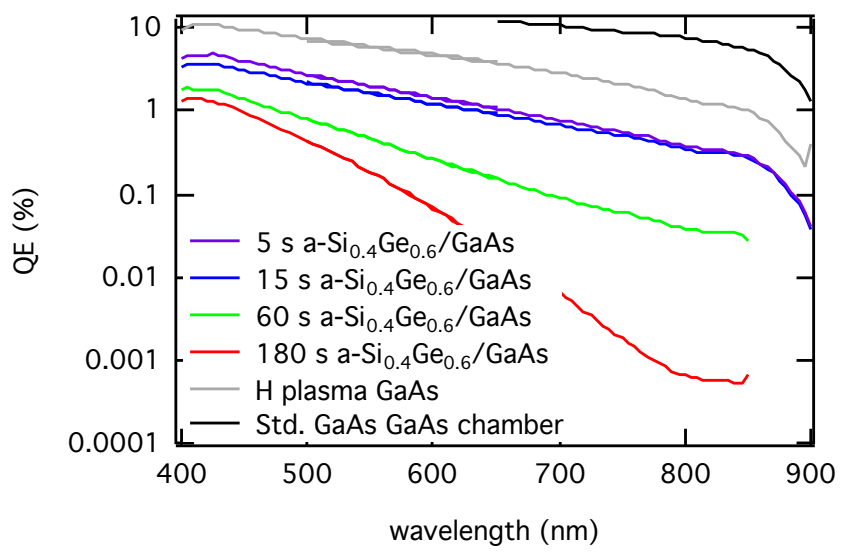

Figure 37. Composite plot of photoyield from a range of thicknesses of a- $\mathrm{Si}_{0.4} \mathrm{Ge}_{0.6}$ films grown on GaAs substrates. Also shown are hydrogen plasma treated GaAs and standard GaAs photoyield data. 
In figure 37, the progression in yield from thicker to thinner a- $\mathrm{Si}_{0.4} \mathrm{Ge}_{0.6}$ overlayers can be readily seen to evolve from that for thick a-Si $\mathrm{S}_{0.4} \mathrm{Ge}_{0.6}$ to that for capped GaAs. The first curve shown, that for 180 seconds growth, is no different than that for the twice thicker film of figure 36 (6 minutes, or 360 seconds). The one minute growth begins to show contribution from the underlying GaAs to the photoyield curve. The two thinnest films clearly shown the shape of GaAs photoemission when compared to the last two data sets, plasma and standard treated GaAs substrates. The latter two sets were acquired so that the photoyield from substrates having received the same treatment as the a-SiGe overlayer samples was available for comparison. The substrates were diamond drilled from wafers so that they fit the RF PECVD sample holder which had been used for round tantalum or glass substrates up to that point. The latter sample also served to illustrate that the process of embedding, drilling, extraction and chemical stripping did not damage the GaAs substrate surface.

The hydrogen plasma treated GaAs substrate served to create a point of comparison as to how high the photoyield could reach for a like-treated GaAs substrate with an infinitesimally thin a$\mathrm{SiGe}$ film grown on it. To this end, the growth temperature was the nominal $180^{\circ} \mathrm{C}$ and the "growth" time was 15 seconds, but with a plasma comprised entirely of hydrogen and having a total flow rate of the sum of the other (absent) gasses. The treated substrate was heat cleaned in the a-Si test chamber to the standard GaAs temperature. These data are to be compared with those of the last curve, which were taken from a GaAs substrate without any exposure to the growth process.

From this data set, several conclusions can be drawn. First, even the thinnest a- $\mathrm{Si}_{0.4} \mathrm{Ge}_{0.6}$ overlayers still presented an emission barrier to the underlying GaAs. This is readily seen as the hydrogen plasma treated GaAs layer outperformed the sample with the thinnest a- $\mathrm{Si}_{0.4} \mathrm{Ge}_{0.6}$ capping layer. Second, the process witness (hydrogen plasma) treated sample was outperformed by the GaAs substrate without any process exposure. Lastly, the substrate preparation process did not adversely affect the GaAs photoemission properties. This conclusion is from comparison of the bare GaAs photoyield data with that for bulk GaAs which had been sized by cleaving, rather than through the diamond drilling process.

The difference in yield between the process witness sample and the standard GaAs sample can have several origins. An outline of the complete process helps make this more transparent. A treated substrate was first installed into the sample holder, inserted into the growth system's loadlock where it immediately was put under vacuum, transferred to the growth chamber where it was docked, then ramped up to $180^{\circ} \mathrm{C}$ over a period of 40 minutes. Plasma exposure at $1 / 4$ Torr for 15 seconds was followed by a one hour cooling period (nominal vacuum $<1 \times 10^{-6}$ Torr) before transfer to the load chamber and removal. For this sample, removal was immediately followed by demounting and installation into the test chamber sample holder and insertion into that system's load chamber followed by pumpdown. 
Time at an elevated temperature in less than UHV conditions leads to further oxidation of the GaAs surface; at the standard heat clean temperature $\left(\sim 550^{\circ} \mathrm{C}\right)$, congruent GaAs evaporation occurs taking with it any thin oxide layer. If the process exposure led to a more oxidized surface, this can (and was) tested by a $\mathrm{NH}_{4} \mathrm{OH}$ dip post process exposure to strip any thick oxide from the surface. Excess oxide may not come off even with the standard heat cleaning and this could lead to the observed lower yield. Exposure to the hydrogen plasma (as the interface will always be) could lead to interactions with atomic hydrogen, which should have a good effect as later heating would remove residual oxygen and carbon, or it could lead to ion damage at the interface. The latter would not be affected by a second $\mathrm{NH}_{4} \mathrm{OH}$ dip post process exposure.

\section{Other germanium concentrations}

Preliminary tests on the photoyield as a function of the Ge concentration were also conducted on the low temperature heated $\left(180^{\circ} \mathrm{C}\right) \mathrm{GaAs}$ substrates. A composite plot of the data covering five values appears below in figure 38. It is clear that the higher germanium concentration films are the best performers. This is a transmission effect rather than a band matching one. As the GaAs photoelectrons become more energetic with respect to the top of the a-SiGe conduction band, they are less likely to scatter on the way to the surface. However, even the best was still not quite a match for the process witness sample (see figure 37), though the trend was very encouraging.

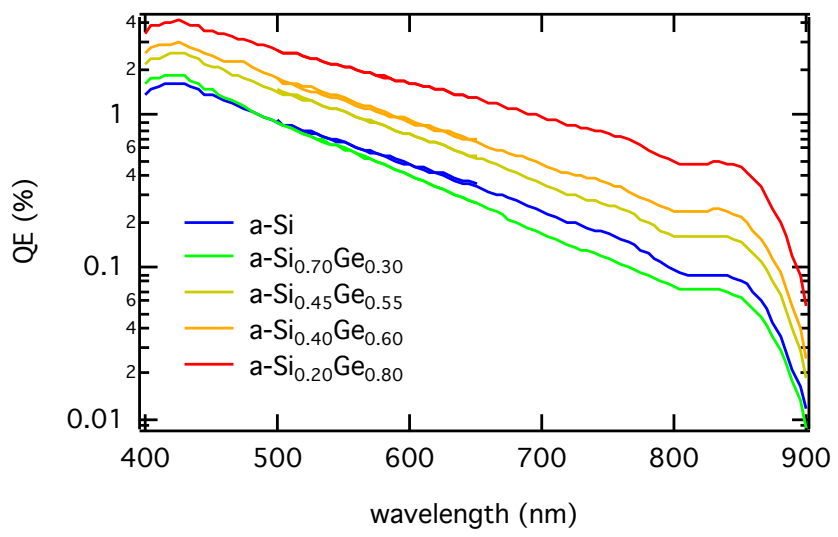

Figure 38. Plot of photoyield as a function of varying germanium concentration for a-SiGe grown on GaAs substrates (15 seconds of $5 \mathrm{~W} \mathrm{RF}$ ). The slight dip at $800 \mathrm{~nm}$ is an artifact from the monochromator grating as its response in the near IR is very weak.

Thin films with heat cleaned GaAs substrates

With the preliminary data, all on bulk GaA, guiding composition and showing needed trends in growth conditions, tests were undertaken on $100 \mathrm{~nm} \mathrm{MBE}$ grown GaAs, the same composition as shown in figure 11(a). Use of this material was implemented as it would best mimic the more expensive strained superlattice type material since emission near the bandgap is limited to the topmost $100 \mathrm{~nm}$, same as for the high polarization material. It was hypothesized that further 
lowering of the RF power during growth of the a-SiGe overlayer could lead to reduced damage. This was shown to be true as can be seen in figure 39. A hydrogen-only plasma as described above was run for $2 \mathrm{~W}$ to ignite the plasma, then it was lowered to $1 \mathrm{~W}$ to finish the exposure. An inline attenuator was used to provide controllably low RF powers. As can be seen by comparison with the sample labeled "bare", the photoyield exhibited little to no decrease outside the normal sample-to-sample variation. The low power growth of the a-SiGe on the $100 \mathrm{~nm} \mathrm{MBE}$ grown substrate, did, however, still diminish the near bandgap photoyield by a factor of $\sim 5$.

Applying the same growth parameters to the arsenic capped high polarization material resulted in the data shown in figure 40. In this case the yield near the high polarization maximum (figure 44) was down a factor of $\sim 3$ from the uncoated material's value. It is not expected that the a-SiGe layer contributes to the photoyield as it's contribution tapers off at lower wavelengths (figure 39).

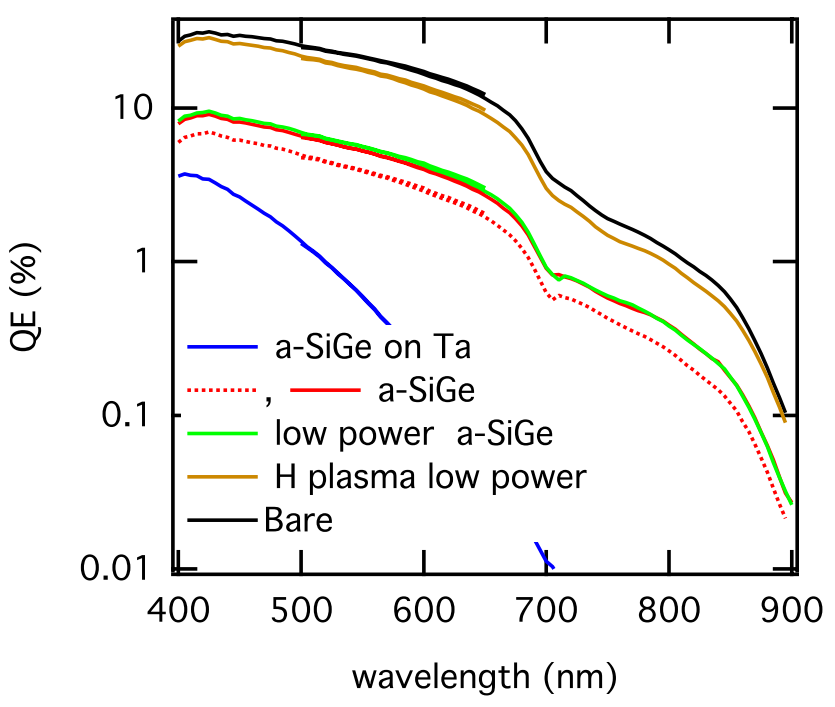

Figure 39. Quantum yield for various treatments of the IQE MBE grown GaAs surface. For contrast, quantum yield for a thick layer of a-SiGe grown on $\mathrm{Ta}$ is shown. In the region of interest (near bandgap), there is very little contribution from the a-SiGe overlayer. The lowest applied hydrogen plasma had only a small effect on the photoyield, if any. 
DE-FG02-07ER84832

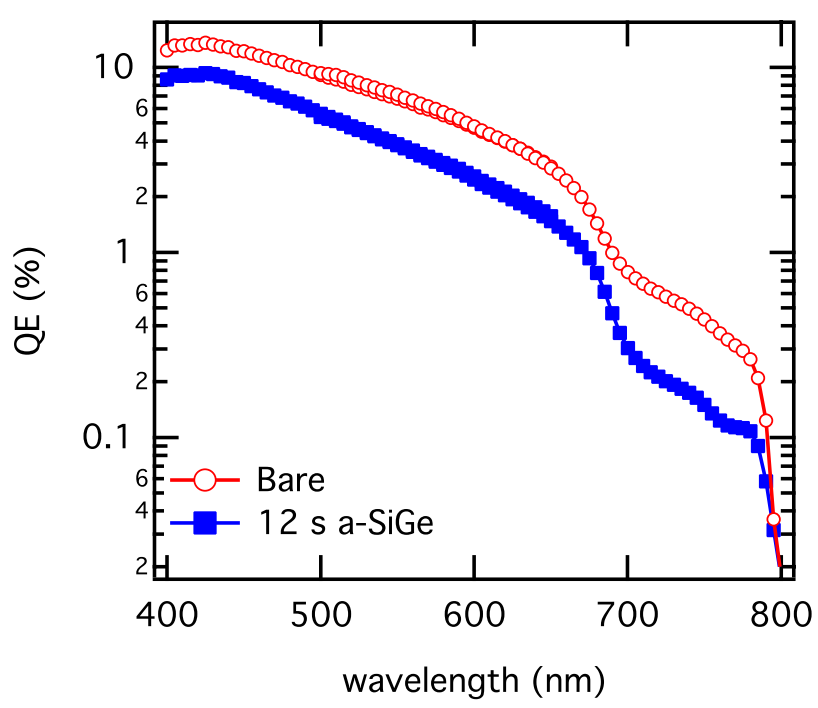

Figure 40. Effect of a-SiGe coating on quantum yield of SVT-grown strained superlattice. The overlayer was grown for $12 \mathrm{sec}$ on the SVT surface after the As capping layer had been desorbed.

Comparison of GaAs composition for bulk and As-capped samples

AES measurements were performed on two GaAs samples to investigate the $\mathrm{Ga} / \mathrm{As}$ composition differences between bulk and As de-capped samples. The bulk GaAs sample was $\mathrm{NH}_{4} \mathrm{OH}$-dipped then immediately loaded into the Auger chamber. The As-capped sample was heated in vacuum to $\sim 600^{\circ} \mathrm{C}$, unloaded and also dipped in $\mathrm{NH}_{4} \mathrm{OH}$ immediately before loading into the Auger chamber. The $\mathrm{NH}_{4} \mathrm{O}$ dips were to remove as much oxide as possible and to provide a consistent chemical preparation starting point. Figure 41 shows the Auger spectra for both samples and the peaks used for compositional analysis. Table 1 shows the atomic fractions calculated from the Auger peak-to-peak intensities scaled by the relative sensitivity factors. The GaAs sample with the As-cap removed shows a slight increase in As composition (and slightly less C).

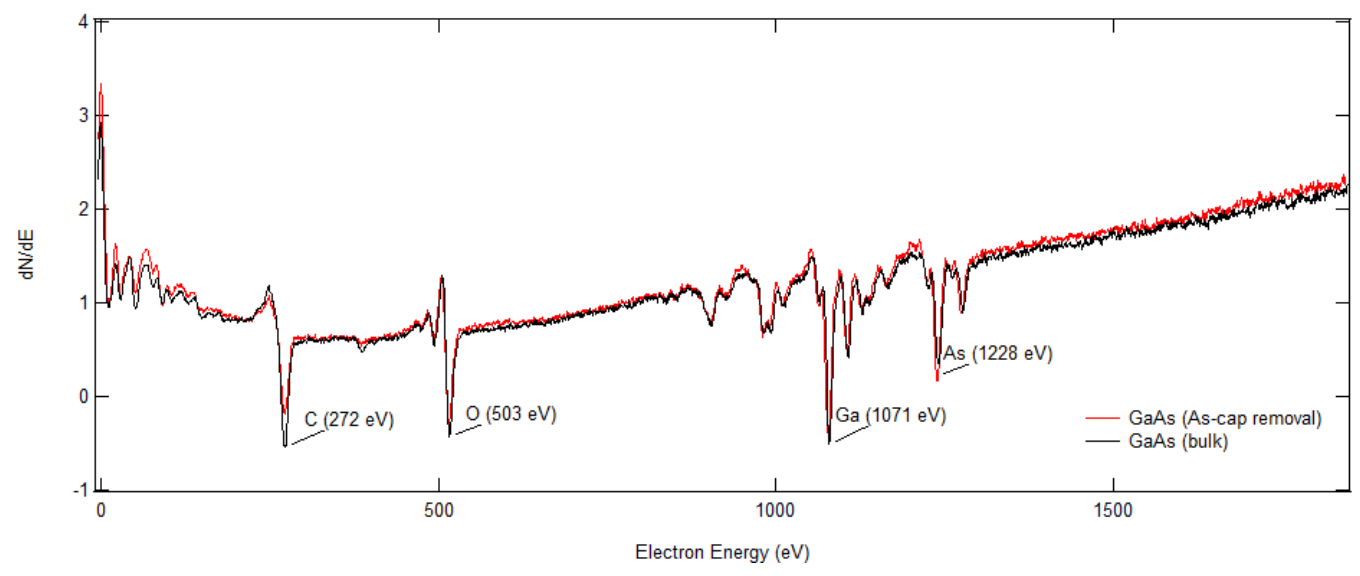

Figure 41: Auger spectra from both bulk GaAs and As-capped GaAs (with heat removal). Peaks used for composition analysis are noted. 


\begin{tabular}{|l|c|c|c|c|}
\hline \multirow{2}{*}{ Sample } & \multicolumn{4}{|c|}{ Atomic fraction } \\
\cline { 2 - 5 } & $\mathrm{C}$ & $\mathrm{O}$ & $\mathrm{Ga}$ & As \\
\hline Bulk GaAs & 0.22 & 0.09 & 0.39 & 0.31 \\
\hline GaAs (As-cap removal) & 0.16 & 0.08 & 0.39 & 0.37 \\
\hline
\end{tabular}

Table 1: Atomic fractions calculated from analyzed Auger peaks for bulk GaAs and As-capped GaAs(with heat removal).

\section{$\underline{\text { SiGe on GaAs composition }}$}

SiGe samples ranging from pure amorphous Si to pure amorphous Ge were analyzed (see table below). All of the samples were first cleaned with an Argon sputter treatment to remove surface contamination. The low energy Si peak $(92 \mathrm{eV})$ has a smaller mean free path than $\mathrm{Ge}(1147 \mathrm{eV})$. This would cause an overestimation of the Ge composition if it were used. The higher energy peak $(1620 \mathrm{eV})$ has a comparable mean free path and is preferred for composition measurements. Also, composition results using the high energy Si peak were not affected by sputtering (not necessary when $\mathrm{C}$ atomic concentrations $\sim 10 \%$ or less). The correlation of the germanium atomic fraction to the germane-to-total flow rate ratio was greatest when using the $1620 \mathrm{eV} \mathrm{Si}$ peak. Only the shortest growth time samples (15 and $5 \mathrm{~s}$ ) had an As peak that could be used for estimated the SiGe film thickness. Greater deposition times generated films that were $>5 \mathrm{~nm}$ thick. Upon calculating the thickness using the Si $1620 \mathrm{eV}$ Auger peak, the overlayer is $\sim 3 \mathrm{~nm}$. The derived value does not vary much with Ge composition. However when using the Ge $1147 \mathrm{eV}$ Auger peak, there is some indication that the films may exhibit greateh thickness with higher Ge composition. This is true for samples with and without sputter cleaning. The trend in signal is shown in figure 42.

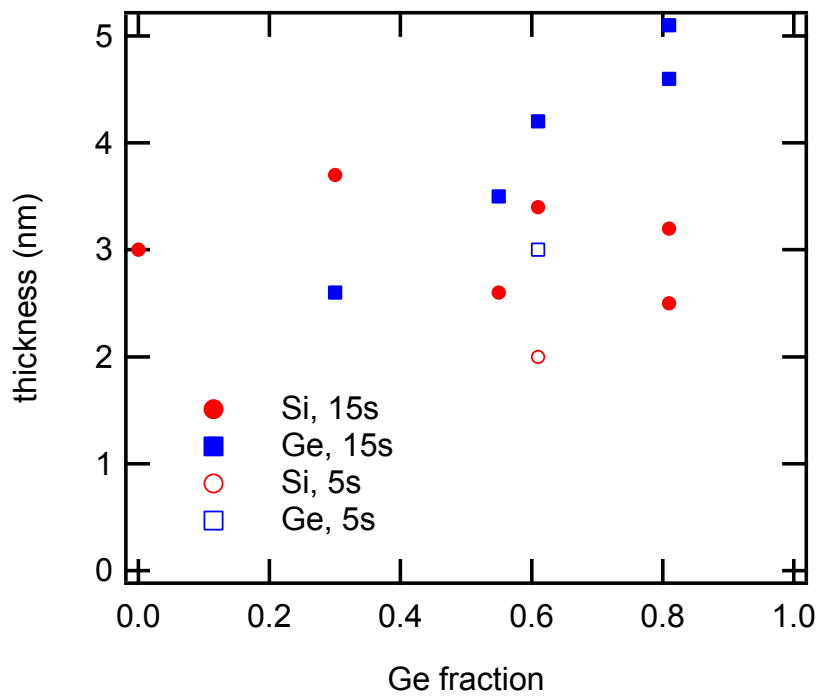

Figure 42. Thickness of a-SiGe overlayers as function of the Ge fraction for the shown growth times. The thicknesses were calculated from elemental Auger signals as labeled. The data suggest a weak dependence of thickness on increasing Ge fraction cannot be entirely ruled out. 


\section{Supplemental AFM measurements}

To explore the surface morphology of the a-SiGe films grown on the GaAs substrates, AFM measurement were taken. An example scan is shown below in figure 43. The lattice constant for crystalline $\mathrm{SiGe} \sim 0.55 \mathrm{~nm}$. The r.m.s. roughness of the sample of figure 50 was $0.2 \mathrm{~nm}$ and was comparable to a bare IQE GaAs substrate. Within the measurement sensitivity of the AFM, the films appear to fully cover the substrate. The thickest sample $(\sim 100 \mathrm{~nm})$ had a large variation is surface height, though it has been previously sputter cleaned. The samples which has experienced either low power or high power $\mathrm{H}_{2}$ plasma only treatments did not show any roughening of the surface. This fact, together with the diminished photoyield for the higher power exposure suggests that the ion bombardment at plasma ignition was sufficient to mildly sputter the interface before the film growth began to protect the interface-to-be.

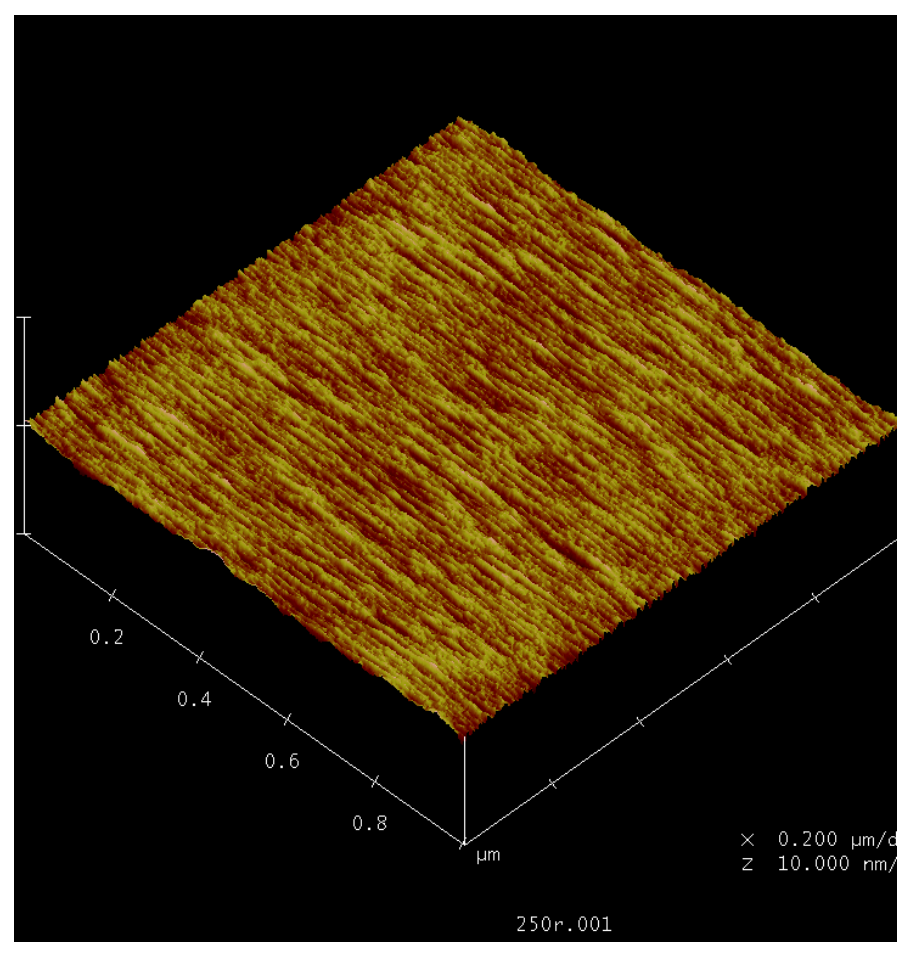

Figure 43. AFM scan of $\mathrm{Si}_{0.2} \mathrm{Ge}_{0.8}$ sample grown on GaAs with starting RF power of $2 \mathrm{~W}$ reduced to $1 \mathrm{~W}$ upon plasma ignition with a total growth time of $5 \mathrm{sec}$. The RMS roughness of the surface was $0.2 \mathrm{~nm}$, approximately that of the bare IQE GaAs substrate.

\section{Effect of a-SiGe layer on electron spin-polarization}

Measurements were performed at SLAC on the a-SiGe/high polarization material both for quantum efficiency and electron spin-polarization. Results are shown below in figure 44 . The relative drop in quantum yield is comparable to that achieved at Saxet. There is a drop of $10 \%$ 
absolute in electron spin-polarization at the wavelength corresponding to the maximum (770 $\mathrm{nm})$. One possible explanation is that the superlattice photocathode was nonuniform. However, over a separate SLAC SBIR, more than 20 wafers were grown and the reproducibility and uniformity was excellent: the peak polarization varied from $\sim 80 \%$ to $85 \%$, but never less than $\sim 78 \%$. SVT-5387 was grown at the end of that work, so it is very unlikely the peak polarization is less than $75 \%$ due to nonuniformity over the wafer. A very plausible model is that the electrons arriving at the surface experience a barrier (photoyield is diminished after all) which causes them to reflect back and forth between the barrier and the band bending region, losing spin polarization in the process. This effect could have been exacerbated by a sub-arsenic cap native oxide layer, incompletely removed via the heat cleaning and arsenic cap desorption process.

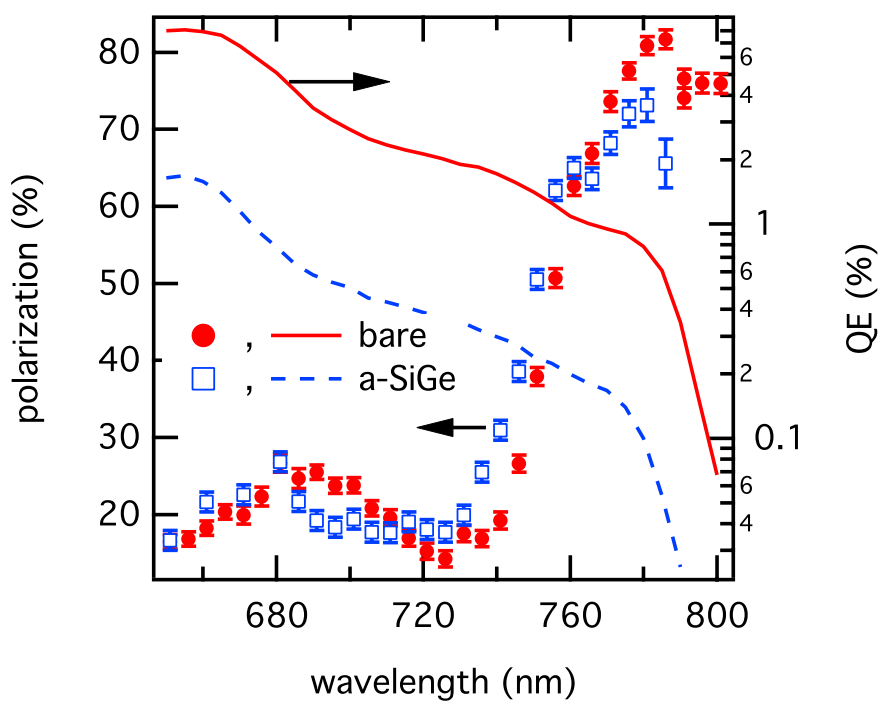

Figure 44. Polarization and quantum yield as a function of wavelength for SVTB704 (strained superlattice) for bare and a-SiGe coated surfaces. Data were taken at SLAC.

\section{End Notes}

1. IQE, Inc., 119 Technology Drive, Bethlehem, PA 18015, (610)861-6930 phone, (610)861-5273 fax.

2. SVT Associates, Inc., 7620 Executive Drive, Eden Prairie, MN 55344, (952)934-2100 phone, (952)934-2737 FAX.

3. Arsenic cap layer desorption and the formation of $\mathrm{GaAs}(001) \mathrm{c}(4 \mathrm{x} 4)$ surfaces, I. Karpov, N. Venkateswaran, G. Bratina, W. Gladfelter, A. Franciosi and L. Sorba, J. Vac. Sci. Technol. B 13, 2041 (1995). 